Research Article

\title{
Parameter Optimization of a Vertical Spring-Viscous Damper-Coulomb Friction System
}

\author{
Biao Wei $\mathbb{D}^{1,2}$ Yi Zhuo $\mathbb{D}^{1,2}$ Chaobin Li $\mathbb{D}^{1,2}$ and Menggang Yang $\mathbb{D}^{1,2}$ \\ ${ }^{1}$ School of Civil Engineering, Central South University, Changsha 410075, China \\ ${ }^{2}$ National Engineering Laboratory for High Speed Railway Construction, Changsha 410004, China \\ Correspondence should be addressed to Chaobin Li; lichaobin@csu.edu.cn
}

Received 27 December 2018; Revised 28 February 2019; Accepted 4 March 2019; Published 14 April 2019

Academic Editor: Mohammad A. Hariri-Ardebili

Copyright (c) 2019 Biao Wei et al. This is an open access article distributed under the Creative Commons Attribution License, which permits unrestricted use, distribution, and reproduction in any medium, provided the original work is properly cited.

A vertical spring-viscous damper-concave Coulomb friction isolation system was firstly proposed, and their parameters were firstly optimized to achieve the best performance under earthquakes. An incremental dynamic analysis method (IDA) and a performance-based assessment framework were used to calculate the system and assess its seismic vulnerability, respectively. Results show that both the friction force and the horizontal component of spring force gradually increase when an earthquake enforce the isolator to slide from its central location. Although other papers propose that an increase of spring force and a decrease of friction force can reduce the structural residual displacement, this paper can minimize the residual displacement value to be 0 by using a super lubrication in the middle of contact surface and a variable increment ratio of concave friction distribution. The reason is that the horizontal component of spring force is always greater than the friction force within any relative displacement between the structure and the ground in this paper. As for the peak relative displacement and peak acceleration of structure, one is reduced while the other is increased when selecting the optimal isolation parameters. If the structure is very sensitive to the acceleration response, a low friction parameter, a small spring constant, and a small and even zero damping constant could be adopted to yield a small peak acceleration of system. The tightness of vertical spring can be adjusted to be appropriately loose to continuously reduce the structural acceleration response.

\section{Introduction}

The traditional isolation devices have some limitations, such as rubber aging under service loadings, resonances due to constant spring stiffness during earthquakes, and a residual displacement after earthquakes $[1,2]$. The experts have investigated a new method of friction-based isolation to achieve a more optimum seismic isolation performance than that of the traditional isolation devices.

Harvey and Gavin [3] investigated a rolling friction platform formed by four pairs of recessed steel bowls to isolate objects under horizontal earthquakes and found that a uniaxial model was not able to predict those seismic responses. Harvey et al. [4] also found that very chaotic behavior including impacts happened for a similar rollingpendulum during earthquakes. Harvey and Gavin [5] identified that the initial conditions, the structural mass, and the disturbance characteristics would influence the seismic isolation performance when studying on double rolling isolation systems (RISs) by using the mathematical and experimental methods. Based on the above influence factors, a simplified mathematical model was presented to successfully predict the responses under different disturbances by Harvey et al. [6]. Furthermore, a new modeling method of reduced order was proposed to calculate the seismic responses of isolated structures using RISs with different damping by Harvey and Gavin [7]. Ismail and Casas [8] validated that a roll-n-cage (RNC) isolator was an efficient solution in protecting bridges $[9,10]$ against the near-fault earthquakes. Wang et al. [11] achieved a perfect in-plane performance isolating earthquakes by using a sloped multiroller isolation device. Ortiz et al. [12] predicted the seismic responses of roller-isolated buildings by using a numerical model and validated it using an experiment. As to reduce the structural displacement responses, the elliptical rolling rods [13] and the rolling-spring device [14] were, respectively, 
used to support the building structures. Antonyuk and Plakhtienko [15] isolated buildings by combining the rolling and unilateral sliding frictions. A bearing using selfcentering and supplemental energy dissipation friction devices was proposed to isolate the highway bridges under earthquakes $[16,17]$. Cui [18] used rubber and polyurethane balls to isolate the building floor in experiments under earthquakes. Guerreiro et al. [19] performed a similar test by using rollers to reduce the seismic acceleration responses of light structures effectively. Tsai et al. [20] used an interchangeable-ball technology between the steel balls and the damping balls to resist the long-term service loadings and the short-term earthquake loads, respectively.

As to further improve the friction-based isolation method, it is necessary to perform a comprehensive evaluation of the different seismic responses of structure using a certain isolation device under earthquakes:

(1) Kurita et al. [21] found that the friction-based isolation devices could reduce the structural peak acceleration response by $50-90 \%$, and Nanda et al. [22] summarized them as the best and simplest devices to isolate earthquake in all kind of isolation devices.

(2) As to reduce the structural relative and residual displacement responses $[23,24]$, some springs and dampers were added to the friction-based isolation devices to offer the restoring and damping forces [25]. However, Chung et al. [26] and Wei et al. [27] found that a too much damping or a too strong spring was inappropriate and would increase the structural acceleration response, and the constant spring stiffness would lead to a resonance during earthquakes. On the contrary, if the restoring devices were weak, the friction force would prevent the structure from returning to its central location and a large residual displacement implied a huge repair cost after earthquakes. Although the shape memory alloy (SMA) devices could solve the above contradiction between the acceleration and displacement responses, they were too expensive to be widely used in practical engineering $[28,29]$.

(3) The shear keys of isolation devices were designed to resist the long-term service loads and would be cut off during some designed earthquakes. However, many factors would disturb the cutting off of shear key. For example, the uneven friction distribution in space [30-32], due to the rough contact surface $[33,34]$, could lead to great uncertain responses $[35,36]$, and the shear keys as well, although they were designed to fail under a certain earthquake.

This paper attempts to further improve the frictionbased isolation method by using a vertical spring-viscous damper-concave Coulomb friction isolation system. When the isolator slides from its central location during an earthquake, the friction force and the horizontal component of spring force gradually increase to reduce the displacement responses. Meanwhile, the above forces are the smallest in the middle of contact surface and can reduce the structural acceleration response within a certain relative displacement and the factors disturbing the cutting off process of shear keys. The shear keys can be reasonably assumed to fail under earthquakes. Finally, the relation between the friction force and the spring force can be adjusted to reduce and even avoid the structural residual displacement.

\section{A Vertical Spring-Viscous Damper-Coulomb Friction Isolation System}

Figure 1 schematically describes an idealized vertical springviscous damper-Coulomb friction isolation system. Table 1 defines all parameters in this system.

2.1. Structural Mass. As to focus on the seismic isolation device and its isolation performance, the isolated structure was assumed as a rigid body with the mass $m$ of 300 ton [25].

2.2. Spring. The spring element remains elastic during earthquakes, and it is able to decrease the relative and residual displacements between the ground and the structure. The spring constant $K$ of vertical spring adopted 100, 200, $300,400,500$, and $600 \mathrm{kN} / \mathrm{m}$, respectively. The length of spring with zero stress is defined as $h_{0}$ while the initial length in Figure 1 is represented by $h_{1}$. The values of $h_{1}$ adopted 0.5 and $1.0 \mathrm{~m}$, respectively. As for the case of $h_{1}=0.5 \mathrm{~m}$, the values of $h_{0}$, respectively, adopted $0.1,0.2,0.3,0.4$, and $0.5 \mathrm{~m}$, and the ratio $h_{0} / h_{1}$ was, respectively, $0.2,0.4,0.6,0.8$, and 1.0. An increase of ratio implies that the spring becomes looser in the initial condition. In terms of the case of $h_{1}=1.0 \mathrm{~m}$, the values of $h_{0}$ respectively adopted $0.1,0.2,0.4,0.6,0.8$, and $1.0 \mathrm{~m}$, and the ratio $h_{0} / h_{1}$ was, respectively, $0.1,0.2,0.4,0.6$, 0.8 , and 1.0 .

When the structural relative displacement $d_{\mathrm{r}}$ happens, the spring force $F_{\mathrm{s}}$ is

$$
F_{\mathrm{s}}=K\left(\sqrt{h_{1}^{2}+d_{\mathrm{r}}^{2}}-h_{0}\right)
$$

The horizontal component $F_{\text {sh }}$ and the vertical component $F_{\mathrm{sv}}$ of spring force are, respectively,

$$
\begin{aligned}
& F_{\mathrm{sh}}=K\left(\sqrt{h_{1}^{2}+d_{\mathrm{r}}^{2}}-h_{0}\right) \frac{d_{\mathrm{r}}}{\sqrt{h_{1}^{2}+d_{\mathrm{r}}^{2}}}, \\
& F_{\mathrm{sv}}=K\left(\sqrt{h_{1}^{2}+d_{\mathrm{r}}^{2}}-h_{0}\right) \frac{h_{1}}{\sqrt{h_{1}^{2}+d_{\mathrm{r}}^{2}}} .
\end{aligned}
$$

When the structural relative displacement $d_{\mathrm{r}}$ is $0, F_{\mathrm{sh}}$ is 0 . Simultaneously, both of the spring force and its vertical component are $K\left(h_{1}-h_{0}\right)$. And those values become 0 if $h_{1}=h_{0}$, which means that the initial condition of spring in Figure 1 has zero stress.

The horizontal secant constant $K_{\mathrm{sh}}$ of spring is

$$
K_{\mathrm{sh}}=K\left(\sqrt{h_{1}^{2}+d_{\mathrm{r}}^{2}}-h_{0}\right) \frac{1}{\sqrt{h_{1}^{2}+d_{\mathrm{r}}^{2}}} .
$$

Equation (4) can also be expressed as 


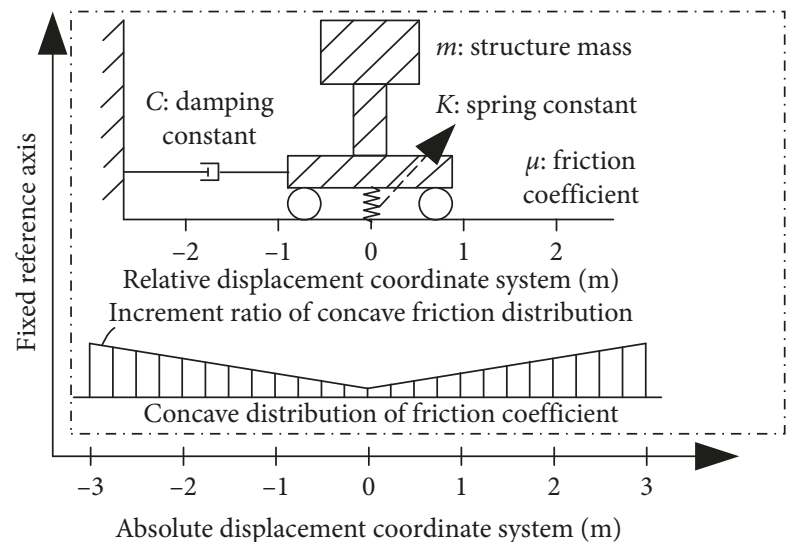

FIgURE 1: A vertical spring-viscous damper-concave friction isolation system.

Table 1: Parameters of the system in Figure 1.

\begin{tabular}{|c|c|c|}
\hline Symbol & Definition & Unit \\
\hline$M$ & The isolated structural mass & ton \\
\hline$C$ & $\begin{array}{l}\text { The damping constant of } \\
\text { viscous damper }\end{array}$ & $\mathrm{kN} \cdot \mathrm{s} / \mathrm{m}$ \\
\hline$K$ & The spring constant of vertical spring & $\mathrm{kN} / \mathrm{m}$ \\
\hline$h_{0}$ & The length of spring with zero stress & $\mathrm{m}$ \\
\hline$h_{1}$ & The initial length of spring in Figure 1 & $\mathrm{~m}$ \\
\hline$F_{s}$ & The spring force & $\mathrm{kN}$ \\
\hline$F_{\text {sh }}$ & The horizontal component of spring force & $\mathrm{kN}$ \\
\hline$F_{\text {sv }}$ & The vertical component of spring force & $\mathrm{kN}$ \\
\hline$K_{\text {sh }}$ & The horizontal secant constant of spring & $\mathrm{kN} / \mathrm{m}$ \\
\hline$\mu$ & The friction coefficient at any position & - \\
\hline$\mu_{0}$ & $\begin{array}{l}\text { The central friction coefficient of concave } \\
\text { friction distribution }\end{array}$ & - \\
\hline$R$ & The friction coefficient increment of unit length & $\mathrm{m}^{-1}$ \\
\hline$V_{\mathrm{d}}$ & The reduced factor based on $r$ in equation (9) & $\mathrm{m}^{-1}$ \\
\hline$F_{\text {fh }}$ & The horizontal friction force & $\mathrm{kN}$ \\
\hline$F_{\text {friction }}$ & The static friction force & $\mathrm{kN}$ \\
\hline$a_{\mathrm{e}}$ & The absolute acceleration of ground & $\mathrm{m} / \mathrm{s}^{2}$ \\
\hline$v_{\mathrm{e}}$ & The absolute velocity of ground & $\mathrm{m} / \mathrm{s}$ \\
\hline$d_{\mathrm{e}}$ & The absolute displacement of ground & $\mathrm{m}$ \\
\hline$a_{\mathrm{s}}$ & The absolute acceleration of structure & $\mathrm{m} / \mathrm{s}^{2}$ \\
\hline$v_{\mathrm{s}}$ & The absolute velocity of structure & $\mathrm{m} / \mathrm{s}$ \\
\hline$d_{s}$ & The absolute displacement of structure & $\mathrm{m}$ \\
\hline$d_{\mathrm{r}}$ & $\begin{array}{l}\text { The relative displacement between the } \\
\text { structure and the ground, } d_{\mathrm{r}}=d_{\mathrm{s}}-d_{\mathrm{e}}\end{array}$ & $\mathrm{m}$ \\
\hline$t_{i}$ & The $i$ th time of ground motion input & s \\
\hline$\Delta t_{i}$ & $\begin{array}{l}\text { The time interval of ground motion input, } \\
\qquad \Delta t_{i}=t_{i}-t_{i-1}\end{array}$ & s \\
\hline
\end{tabular}

$$
K_{\mathrm{sh}}=K\left(1-\frac{1}{\sqrt{\left(h_{1} / h_{0}\right)^{2}+\left(d_{\mathrm{r}} / h_{0}\right)^{2}}}\right) \text {. }
$$

2.3. Viscous Damper. The viscous damper can produce a viscous damping force and dissipate earthquake energy during earthquakes. The damping constants $C$ adopted 0, 50, $100,150,200$, and $250 \mathrm{kN} \cdot \mathrm{s} / \mathrm{m}$ in this paper.
2.4. Coulomb Friction. In this system, the friction device supports the superstructure and isolates the earthquake input motion. During a seismic event, it could induce friction force at the bottom of structure to balance the inertial force developed in the superstructure, and dissipate the earthquake energy. Despite the fact that both the friction device and the viscous damper can dissipate the earthquake energy, the viscous damping force is dependent on the damping constant and the relative velocity while the friction force is a function of the structural mass and the friction coefficient [37]. Furthermore, the friction force prevents the structure from returning to its central location after earthquakes [38]; however, the viscous damping force does not have such a negative effect.

As to reduce this negative effect, the general nonuniform distribution of friction coefficient is artificially changed into the concave one as illustrated in Figure 1. The friction coefficient is expressed as

$$
\mu=\mu_{0}+r\left|d_{\mathrm{r}}\right| .
$$

The central friction coefficient $\mu_{0}$ was the smallest one in all, and adopted $0.005,0.01,0.02$ and 0.1 , respectively, in this paper. When the relative displacement $d_{\mathrm{r}}$ increases between the ground and the structure, the friction coefficient $\mu$ grows. The friction coefficient increment of unit length was defined as the increment ratio $r$ of concave friction distribution and was assumed to be $0.01,0.02,0.03,0.04$, and $0.1 \mathrm{~m}^{-1}$, respectively. Therefore, the horizontal friction force $F_{\mathrm{fh}}$ is

$$
F_{\text {fh }}=\left(\mu_{0}+r\left|d_{\mathrm{r}}\right|\right)\left[\mathrm{mg}+K\left(\sqrt{h_{1}^{2}+d_{\mathrm{r}}^{2}}-h_{0}\right) \frac{h_{1}}{\sqrt{h_{1}^{2}+d_{\mathrm{r}}^{2}}}\right] \text {. }
$$

When $d_{\mathrm{r}}$ increases during earthquakes, the friction force increases to dissipate the earthquake energy more significantly to avoid a larger relative displacement owing to the concave friction distribution and the increased vertical component of spring force. Simultaneously, the horizontal component of spring force also increases to reduce the relative and residual displacements of structure. Theoretically, the system in Figure 1 is reasonable to reduce the structural seismic responses. And it is necessary to carry out the parameter optimization analysis of the system.

2.5. Shear Key. When $d_{\mathrm{r}}=0$, the horizontal component of spring force is 0 , and the friction force is very small because of the concave friction distribution. Therefore, a shear key was artificially designed in the isolation device to resist the long-term service loadings. The cutting off of shear key was permitted under large earthquakes only. And the cutting off process of shear key will not be disturbed significantly, because the horizontal spring force and friction force was so small when $d_{\mathrm{r}}=0$.

\section{Ground Motion}

An elastic response spectrum was selected for the target spectrum with the soil type III in Chinese criteria [39] as shown in Figure 2, because the related seismic safety report 


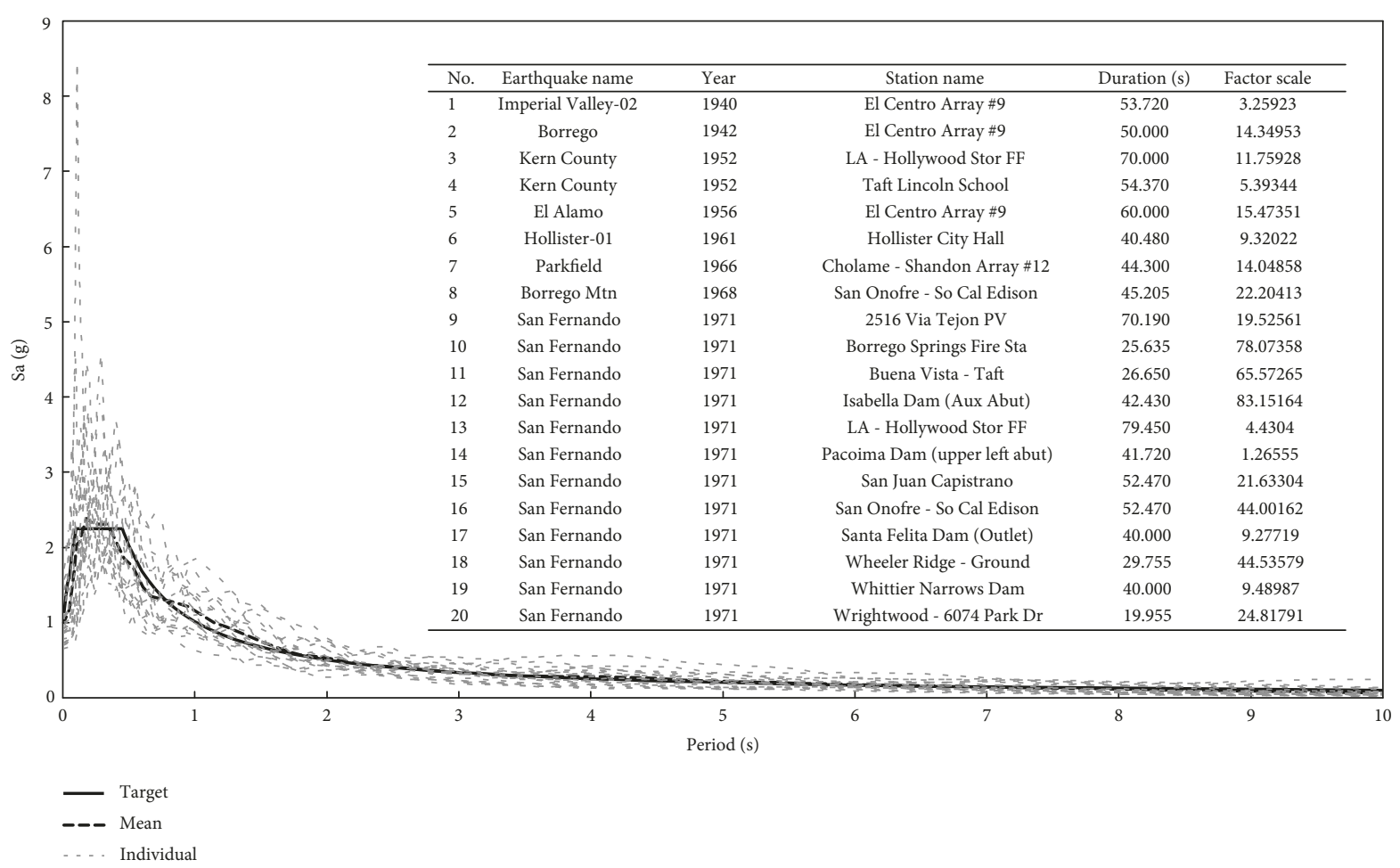

FIGURE 2: Target spectrum, mean spectrum, and individual earthquake spectra $(P G A=1 \mathrm{~g})$.

showed that the relatively soft soil with a shear wave velocity between 140 and $250 \mathrm{~m} / \mathrm{s}$ was very thick for the structural site.

Twenty ground motions, selected from the Pacific Earthquake Engineering Research Center database (PEER, 2015), were scaled in accordance with the target spectrum with a peak ground acceleration (PGA) of $1 \mathrm{~g}$ in Figure 2. And their average spectrum was close to the target one.

The above scaled ground motions were continuously scaled to meet the target spectrum with different PGA from $0.01 \mathrm{~g}$ to $1 \mathrm{~g}$ with an increment of $0.01 \mathrm{~g}$, and they were input into the isolation structure as ground motion excitations.

There was an assumption here that the increase of PGA did not prolong the predominant period of earthquakes, which was different from the fact. This assumption was only used to reduce the influence of more complex ground motion characteristics on the study object in this paper, i.e., the seismic isolation device and its isolation performance.

\section{Calculation Method}

A computer program was compiled to calculate the seismic responses of the vertical spring-viscous damper-Coulomb friction system, and its mathematical foundation is listed in the following content.

Figure 1 defines the absolute coordinate system of ground motion and structural motion. The absolute acceleration, velocity, and displacement of ground are defined, respectively, as the terms $a_{\mathrm{e}}, v_{\mathrm{e}}$, and $d_{\mathrm{e}}$ and $a_{\mathrm{s}}, v_{\mathrm{s}}$, and $d_{\mathrm{s}}$ are the similar terms of structure. The relationship between $v_{\mathrm{e}}$ and $v_{\mathrm{s}}$ could lead to three different scenarios as follows (Figure 3):
(1) $v_{\mathrm{e}}>v_{\mathrm{s}}$. This case indicates that the structure moves relative to and more slowly than the ground. There is a combination force of spring, viscous damper, and friction, i.e., $\left[F_{\mathrm{fh}}+F_{\mathrm{sh}}+C\left(v_{\mathrm{e}}-v_{\mathrm{s}}\right)\right]$, acting on the structure.

(2) $v_{\mathrm{e}}<v_{\mathrm{s}}$. This case indicates that the structure moves relative to and faster than the ground. There is a combination force $\left[-F_{\mathrm{fh}}+F_{\mathrm{sh}}+C\left(v_{\mathrm{e}}-v_{\mathrm{s}}\right)\right]$ acting on the structure. The sign of friction force becomes “_" relative to case (1).

At a certain time step of cases (1) and (2), if $\left|\left[\left(v_{\mathrm{s}}-v_{\mathrm{e}}\right)+F_{\mathrm{sh}} \Delta t_{i} / m+C\left(v_{\mathrm{e}}-v_{\mathrm{s}}\right) \Delta t_{i} / m\right]\right| \leq F_{\mathrm{fh}} \Delta t_{i} / m$ and $\left|\left[a_{\mathrm{e}}-F_{\mathrm{sh}} / m-C\left(v_{\mathrm{e}}-v_{\mathrm{s}}\right) / m\right]\right| \leq F_{\mathrm{fh}} / m$, the system will move to case (3), i.e., $v_{\mathrm{e}}=v_{\mathrm{s}}$, where $\Delta t_{i}=$ $t_{i}-t_{i-1}$ and $t_{i}$ is the $i$ th time of the ground motion input.

(3) $v_{\mathrm{e}}=v_{\mathrm{s}}$. This implies that the structure moves with the same velocity of ground. The equation of motion can be expressed as $m a_{\mathrm{e}}= \pm F_{\text {friction }}+F_{\mathrm{sh}}+C\left(v_{\mathrm{e}}-v_{\mathrm{s}}\right)$, where $F_{\text {friction }} \leq F_{\mathrm{fh}}$. And the equation is further simplified as $m a_{\mathrm{e}}= \pm F_{\text {friction }}+F_{\text {sh }}$ since $v_{\mathrm{e}}=v_{\mathrm{s}}$, or $\left|\left[a_{\mathrm{e}}-F_{\mathrm{sh}} / m\right]\right|=F_{\text {friction }} / m \leq F_{\mathrm{fh}} / m$. In order to estimate the structural response at the next time step, it is necessary to compare $\left|\left[a_{\mathrm{e}}-F_{\mathrm{sh}} / m\right]\right|$ with $F_{\mathrm{fh}} / m$.

(a) When $\left|a_{\mathrm{e}}-\left[F_{\mathrm{sh}} / m\right]\right| \leq F_{\mathrm{fh}} / m$, the inertia force developed in the structure is not able to trigger the relative movement between the structure and the ground. Therefore, the structural acceleration $a_{\mathrm{s}}$ is the same as the ground acceleration $a_{\mathrm{e}}$. 


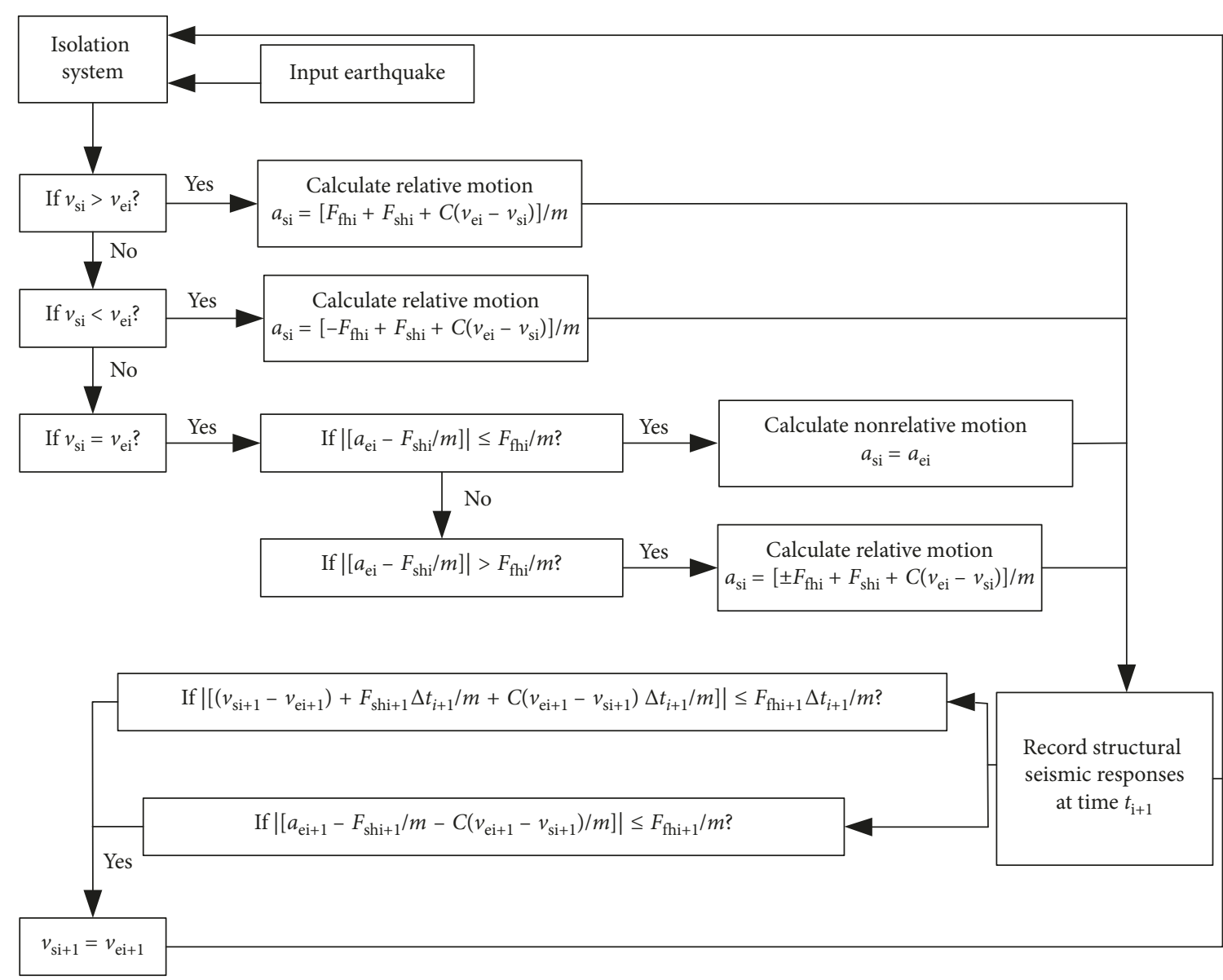

Figure 3: Flow chart of calculation method.

(b) When $\left|\left[a_{\mathrm{e}}-F_{\mathrm{sh}} / m\right]\right|>F_{\mathrm{fh}} / m$, the instantaneous ground motion is intense enough to develop the new relative movement of structure. Therefore, the resultant force on the structure could be mathematically expressed as $\left[ \pm F_{\mathrm{fh}}+F_{\mathrm{sh}}+C\right.$ $\left.\left(v_{\mathrm{e}}-v_{\mathrm{s}}\right)\right]$. Note that the sign of friction force $F_{\mathrm{fh}}$ depends on the direction of $a_{\mathrm{e}} \cdot v_{\mathrm{e}}$ will be different from $v_{s}$ and the system will move to case (1) or (2) at the next time step.

\section{Performance-Based Assessment Process}

The PEER performance-based assessment framework [40] is simplified to only include the response analysis and the damage analysis to assess the seismic performance of structure listed in Section 2. For the assessment of seismic vulnerability, the seismic hazard analysis and the loss analysis are not included in the framework temporarily.

A large quantity of responses was gained by an incremental dynamic analysis (IDA), using the ground motion records in Section 3 and the calculation method in Section 4. Those responses contain the statistical distribution of response values at different earthquake intensities.

The damage states (DS) of structural system are defined in Table 2. The structural peak acceleration response directly reflects the degree of the earthquake damage to
TABLE 2: Damage states of structural system.

\begin{tabular}{lccccc}
\hline Index & Units & DS1 & DS2 & DS3 & DS4 \\
\hline Acceleration & $\mathrm{m} / \mathrm{s}^{2}$ & 0.25 & 0.50 & 0.75 & 1.00 \\
Relative displacement & $\mathrm{m}$ & 0.20 & 0.40 & 0.80 & 1.60 \\
Residual displacement & $\mathrm{m}$ & 0.02 & 0.04 & 0.08 & 0.16 \\
\hline
\end{tabular}

the isolated structure, and this is the most important index of seismic isolation. The structural relative displacement, which indicates whether the structure will separate from its foundation and whether the structure will collide with other neighboring structures, is also of concern for the isolated structure. If the structural foundation and the gap between the structure and other adjacent structures are all large enough, the structural relative displacement will become an ignored factor; however, it will increase the structural cost in the construction phase. To reduce the loss of reparation and service breakdown, the isolator will be expected to return to its central location without a considerable residual displacement after earthquakes. Therefore, the seismic vulnerability analysis is carried out to obtain the optimum parameters of isolation system, achieving the small acceleration response and the small relative displacement during earthquakes, and the small or even zero residual displacement after earthquakes. 
TABLe 3: Parameter values of the system in Figure 1.

\begin{tabular}{lcc}
\hline Symbol & Values & Unit \\
\hline$M$ & 300 & ton \\
$C$ & $0,50,100,150,200$, and 250 & $\mathrm{kN} \cdot \mathrm{s} / \mathrm{m}$ \\
$K$ & $100,200,300,400,500$, and 600 & $\mathrm{kN} / \mathrm{m}$ \\
$h_{0}$ & $h_{0}=0.1,0.2,0.3,0.4$, and $0.5 \mathrm{~m}$, when $h_{1}=0.5 \mathrm{~m} ;$ & $\mathrm{m}$ \\
$h_{1}$ & $h_{0}=0.1,0.2,0.4,0.6,0.8$, and $1.0 \mathrm{~m}$, when $h_{1}=1.0 \mathrm{~m}$ & $\mathrm{~m}$ \\
$\mu_{0}$ & 0.5 and 1.0 & - \\
$r$ & $0.005,0.01,0.02$, and 0.1 & $\mathrm{~m}^{-1}$ \\
$V_{\mathrm{d}}$ & $0.01,0.02,0.03,0.04$, and 0.1 & $\mathrm{~m}^{-1}$ \\
\hline
\end{tabular}
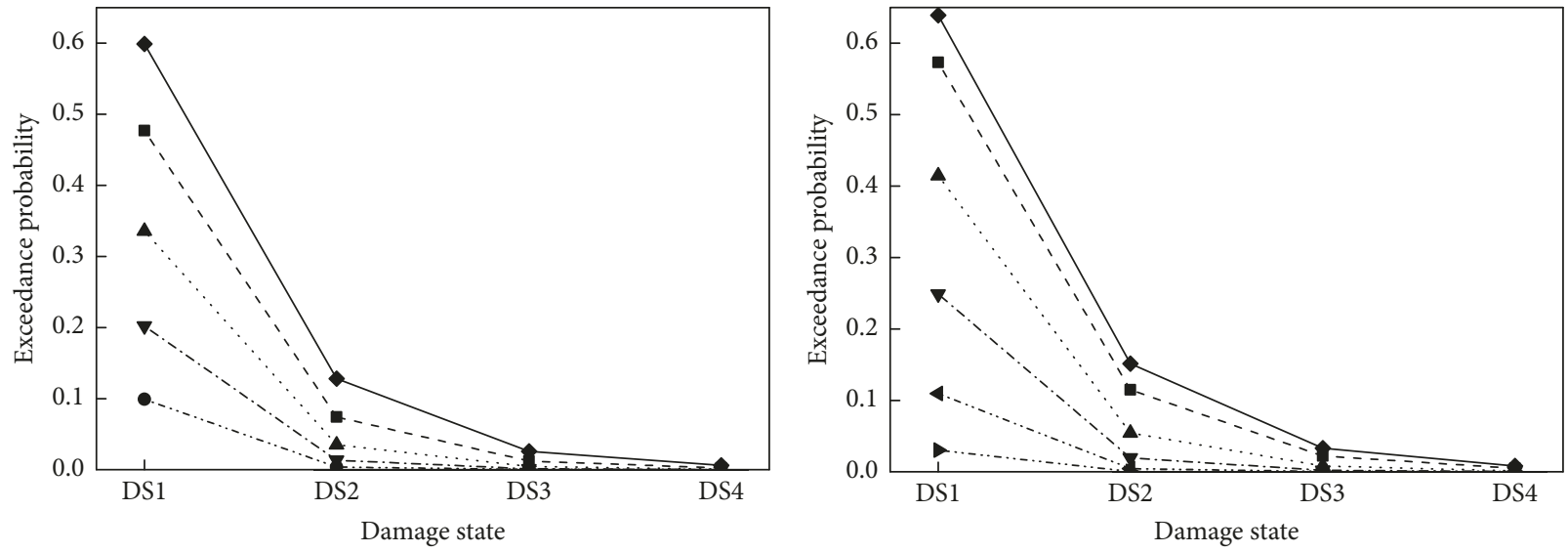

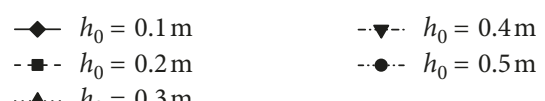

(a)

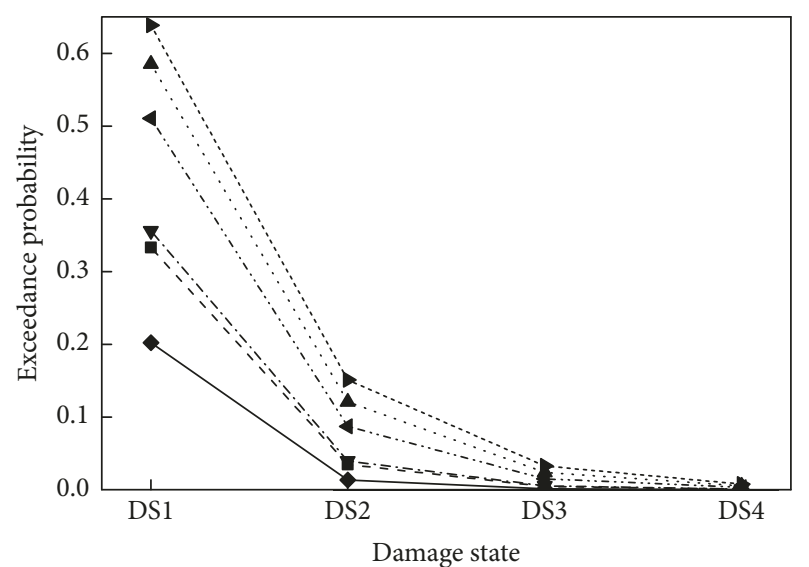

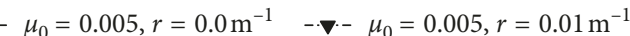

$$
\begin{aligned}
& \text { - } \mu_{0}=0.01, r=0.0 \mathrm{~m}^{-1} \quad-\quad \mu_{0}=0.005, r=0.02 \mathrm{~m}^{-1} \\
& \text {-. } \mu_{0}=0.02, r=0.0 \mathrm{~m}^{-1} \quad \cdots \cdots \mu_{0}=0.005, r=0.03 \mathrm{~m}^{-1}
\end{aligned}
$$

(c)

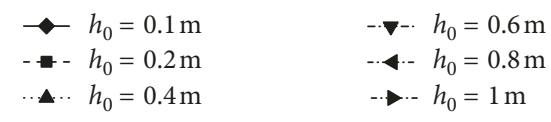

(b)

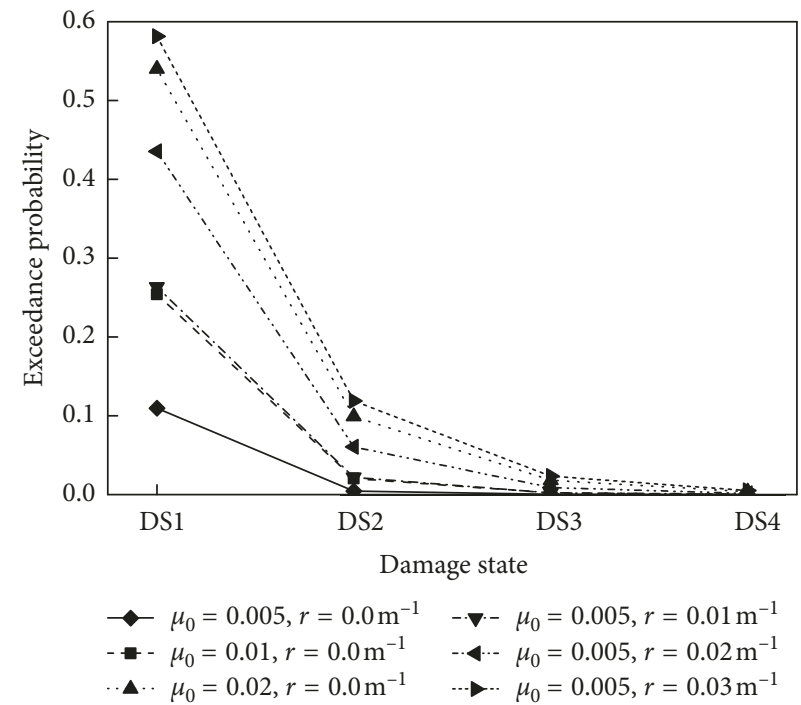

(d)

FIGURE 4: Structural peak acceleration when $K=100 \mathrm{kN} / \mathrm{m}, C=0 \mathrm{kN} \cdot \mathrm{s} / \mathrm{m}$, and PGA $=0.8 \mathrm{~g}$ (the horizontal ordinate DS1, DS2, DS3, and DS4 are defined by the structural peak acceleration in Table 2). (a) $\mu_{0}=0.005, r=0.0 \mathrm{~m}^{-1}, h_{1}=0.5 \mathrm{~m}$. (b) $\mu_{0}=0.005, r=0.0 \mathrm{~m}^{-1}, h_{1}=1.0 \mathrm{~m}$. (c) $h_{1}=0.5 \mathrm{~m}, h_{0}=0.4 \mathrm{~m}$. (d) $h_{1}=1.0 \mathrm{~m}, h_{0}=0.8 \mathrm{~m}$. 


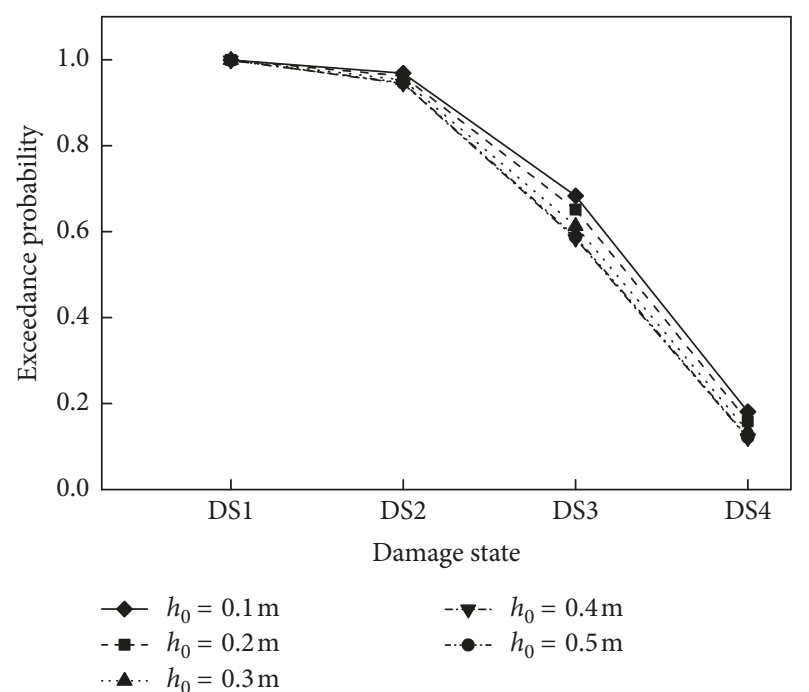

(a)

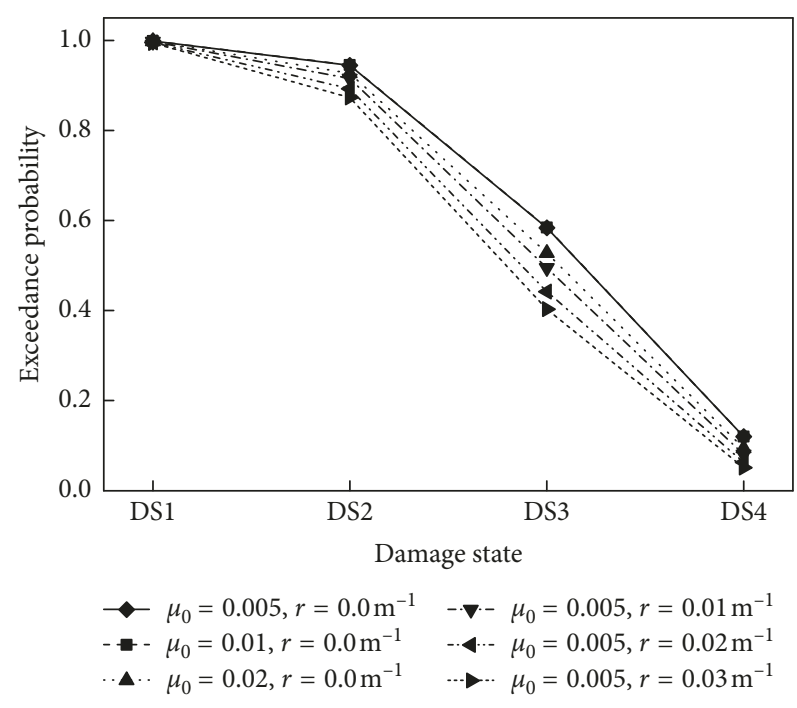

(c)
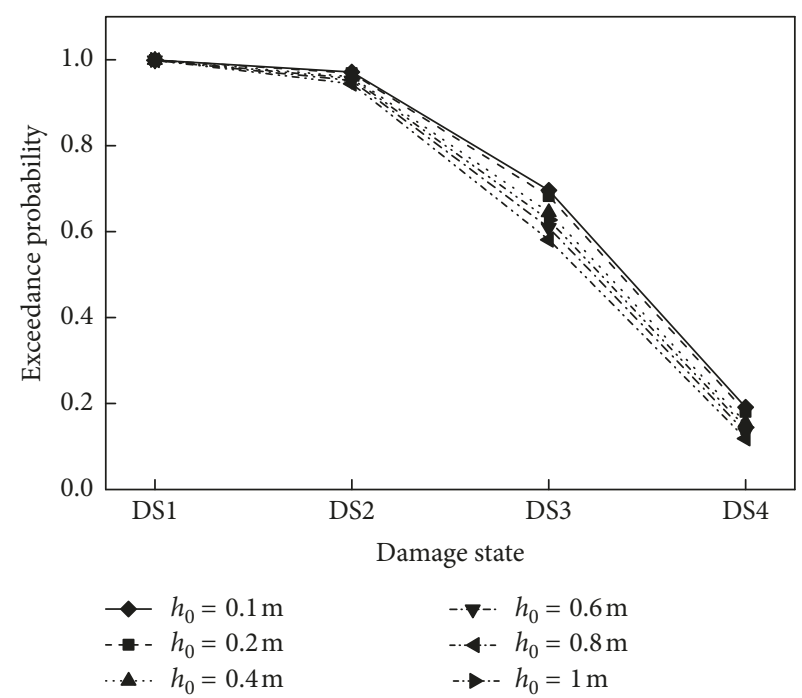

(b)

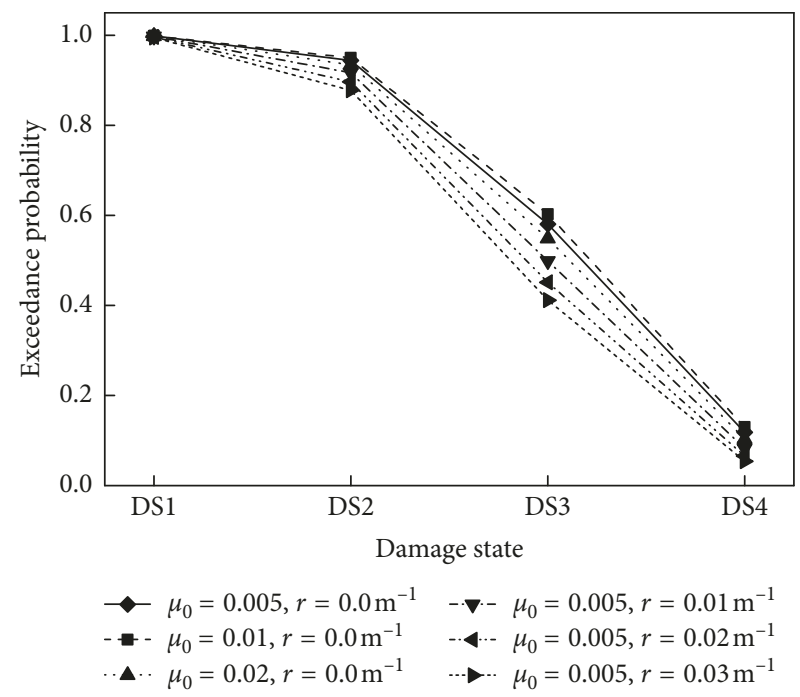

(d)

Figure 5: Structural peak relative displacement when $K=100 \mathrm{kN} / \mathrm{m}, C=0 \mathrm{kN} \cdot \mathrm{s} / \mathrm{m}$, and PGA $=0.8 \mathrm{~g}$ (the horizontal ordinate DS1, DS2, DS3, and DS4 are defined by the structural peak relative displacement in Table 2). (a) $\mu_{0}=0.005, r=0.0 \mathrm{~m}^{-1}, h_{1}=0.5 \mathrm{~m}$. (b) $\mu_{0}=0.005, r=0.0 \mathrm{~m}^{-1}$, $h_{1}=1.0 \mathrm{~m}$. (c) $h_{1}=0.5 \mathrm{~m}, h_{0}=0.4 \mathrm{~m}$. (d) $h_{1}=1.0 \mathrm{~m}, h_{0}=0.8 \mathrm{~m}$.

\section{Performance-Based Assessment Results}

In Section 2, 7920 cases were obtained by combining 1 structure mass, 6 damping constants, 20 friction cases, and 66 spring cases in Table 3 for the isolation system in Figure 1. For each case, each acceleration diagram in Section 3 was used as ground motion input to carry out the incremental dynamic analysis (IDA), and the intensity measure (IM) was the PGA of the average seismic spectrum or Sa. Finally, the seismic response demands of 15840000 cases were obtained and compared with the seismic capacities in Table 2. A lot of vulnerability curves are obtained; however, this section discusses only classic and common curves in detail while others are not listed due to space limitations.
6.1. Cases with a Weak Spring and without a Viscous Damper. The probabilities, exceeding each damage state (DS1, DS2, DS3, and DS4) in Table 2, of the cases with $K=100 \mathrm{kN} / \mathrm{m}$, $C=0 \mathrm{kN} \cdot \mathrm{s} / \mathrm{m}$, and other different parameters subjected to the earthquakes with PGA $=0.8 \mathrm{~g}$ are shown in Figures 4-6.

In Figures 4(a) and 4(b), the exceedance probabilities of DS1, DS2, DS3, and DS4, defined by the structural peak acceleration in Table 2, decrease when the ratio of the spring length $h_{0}$ with zero stress to the initial spring length $h_{1}$ becomes larger, i.e., the spring becomes looser. Those phenomena can be explained by equation (5). By keeping other parameters unchanged, an increase of $h_{0} / h_{1}$ will decrease the horizontal secant constant $K_{\text {sh }}$ of spring in equation (5), and thus decrease the structural acceleration 


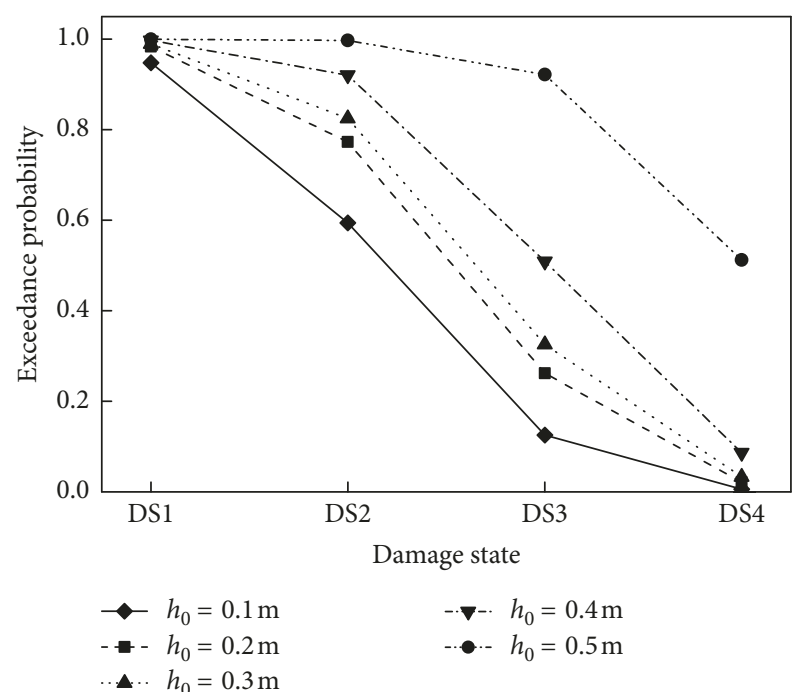

(a)

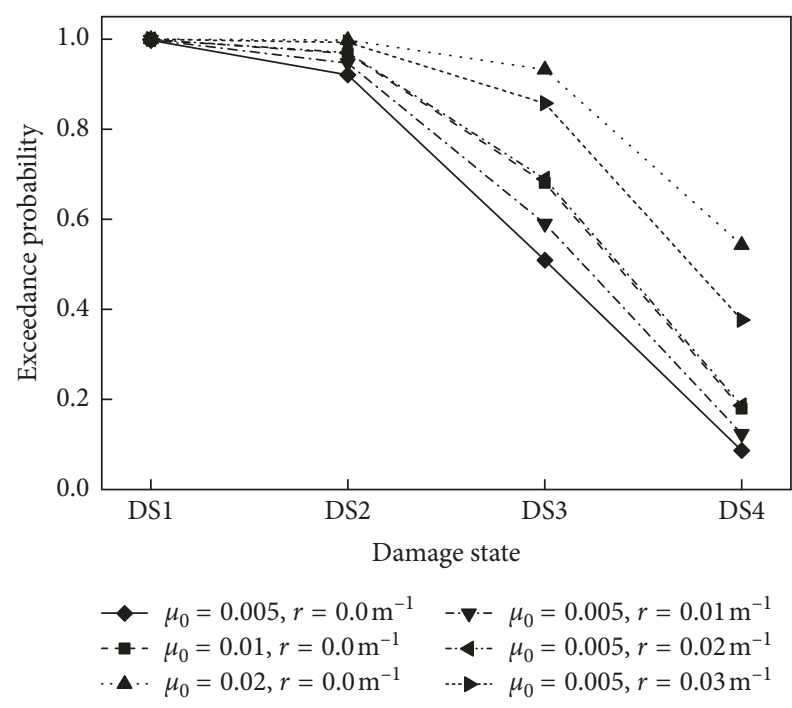

(c)

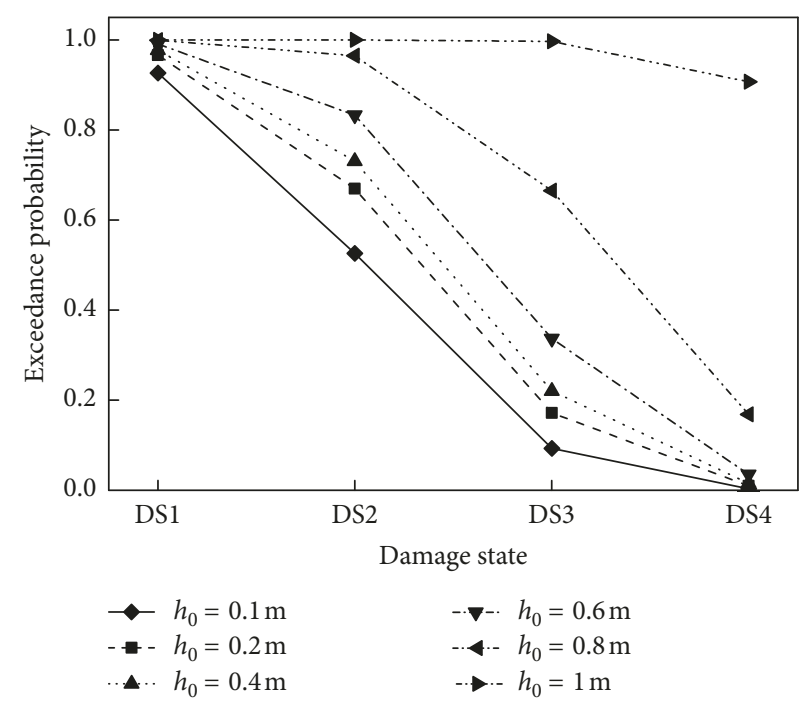

(b)

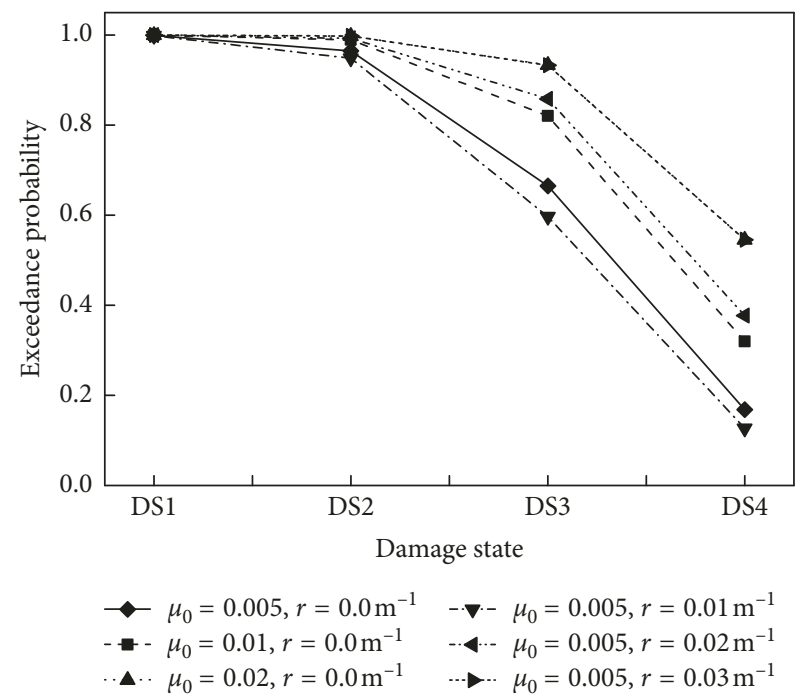

(d)

FIGURE 6: Structural residual displacement when $K=100 \mathrm{kN} / \mathrm{m}, C=0 \mathrm{kN} \cdot \mathrm{s} / \mathrm{m}$, and PGA $=0.8 \mathrm{~g}$ (the horizontal ordinates DS1, DS2, DS3, and DS4 are defined by the structural residual displacement in Table 2). (a) $\mu_{0}=0.005, r=0.0 \mathrm{~m}^{-1}, h_{1}=0.5 \mathrm{~m}$. (b) $\mu_{0}=0.005, r=0.0 \mathrm{~m}^{-1}$, $h_{1}=1.0 \mathrm{~m}$. (c) $h_{1}=0.5 \mathrm{~m}, h_{0}=0.4 \mathrm{~m}$. (d) $h_{1}=1.0 \mathrm{~m}, h_{0}=0.8 \mathrm{~m}$.

responses since the instantaneous natural period of structure becomes longer [25]. However, the corresponding restoring force will be reduced and the structural residual displacement will be increased [26]. It is validated by the exceedance probabilities of DS1, DS2, DS3, and DS4, defined by the structural residual displacement in Table 2, in Figures 6(a) and 6(b). In Figures 5(a) and 6(b), the exceedance probabilities of DS1, DS2, DS3, and DS4, defined by structural peak relative displacement in Table 2, seem to have the critical parameters $h_{0} / h_{1}$ aiming at the minimum value [25]. The reason is that the decrease of the horizontal secant constant $K_{\text {sh }}$ of spring in equation (5), due to an increase of $h_{0} / h_{1}$, will cause the increased instantaneous natural period of structure to be close to or far away from a certain long period component of earthquakes.
Because the instantaneous natural period of structure is more than $10 \mathrm{~s}$ and the earthquake energy around this period is very small, the influence of $h_{0} / h_{1}$ on the structural peak relative displacement is insignificant in Figures 5(a) and 5(b).

By keeping the same $h_{0} / h_{1}$ in equation (5), an increase of the initial spring length $h_{1}$ implies that the spring length $h_{0}$ with zero stress is also increased. It decreases the term of $d_{\mathrm{r}} / h_{0}$ and thus the horizontal secant constant $K_{\mathrm{sh}}$ of spring in equation (5). Being like the discussion in the above paragraph, it will further decrease the structural peak acceleration, increase the structural residual displacement, and increase or decrease the structural relative displacement. Those predicted phenomena are identified by comparing (c) and (d) in Figures 4-6. 


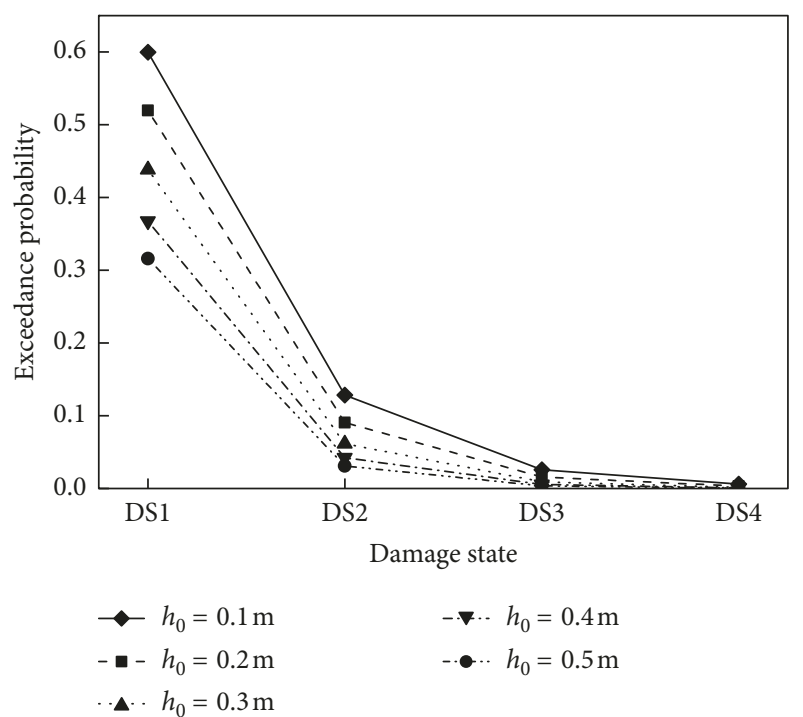

(a)

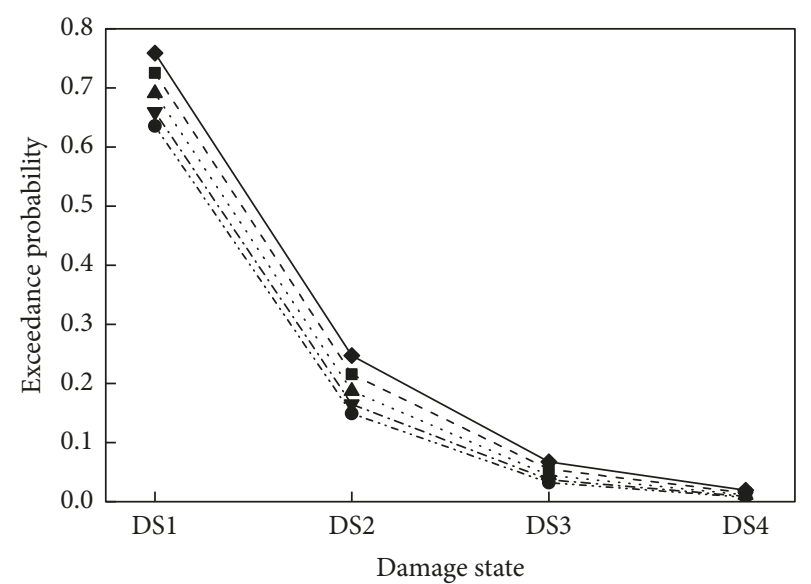

$$
\begin{aligned}
& \multimap h_{0}=0.1 \mathrm{~m} \\
& -\bullet h_{0}=0.2 \mathrm{~m} \\
& \therefore-h_{0}=0.3 \mathrm{~m}
\end{aligned}
$$

$-\nabla \cdot h_{0}=0.4 \mathrm{~m}$

- $h_{0}=0.5 \mathrm{~m}$

(c)

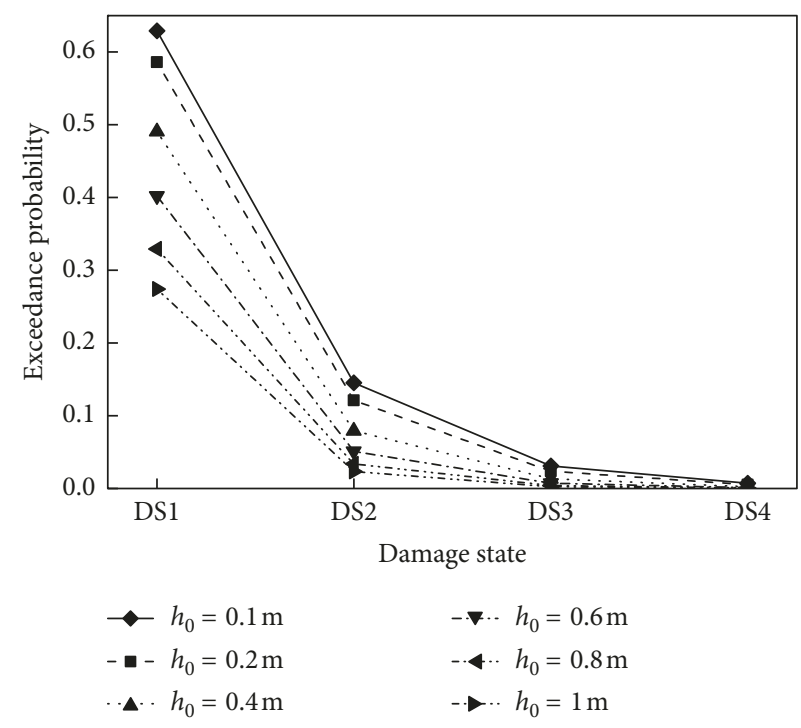

(b)

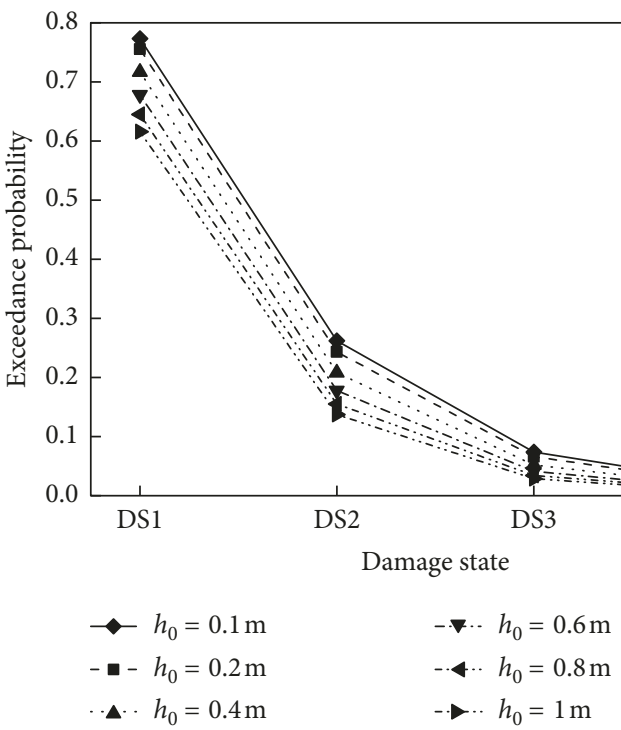

(d)

FIGURE 7: Structural peak acceleration when $K=100 \mathrm{kN} / \mathrm{m}$ with different damping constants, PGA $=0.8 \mathrm{~g}$ (the horizontal ordinates DS1, DS2, DS3, and DS4 are defined by the structural peak acceleration in Table 2). (a) $\mu_{0}=0.005, r=0.0 \mathrm{~m}^{-1}, h_{1}=0.5 \mathrm{~m}, C=50 \mathrm{kN} \cdot \mathrm{s} / \mathrm{m}$. (b) $\mu_{0}=0.005, r=0.0 \mathrm{~m}{ }^{-1}$, $h_{1}=1.0 \mathrm{~m}, C=50 \mathrm{kN} \cdot \mathrm{s} / \mathrm{m}$. (c) $\mu_{0}=0.005, r=0.0 \mathrm{~m}^{-1}, h_{1}=0.5 \mathrm{~m}, C=100 \mathrm{kN} \cdot \mathrm{s} / \mathrm{m}$. (d) $\mu_{0}=0.005, r=0.0 \mathrm{~m}^{-1}, h_{1}=1.0 \mathrm{~m}, C=100 \mathrm{kN} \cdot \mathrm{s} / \mathrm{m}$.

In (c) and (d) of Figures $4-6$, the exceedance probabilities increase for the structural peak acceleration and residual displacement and decrease for the structural relative displacement when the friction coefficient $\mu_{0}$ or the increment ratio $r$ of concave friction distribution increases. Those phenomena can be explained by equation (7). An increase of the friction coefficient $\mu_{0}$ or the increment ratio $r$ of concave friction distribution will increase the horizontal friction force $F_{\mathrm{fh}}$ and thus the structural inertia force. The increase of structural inertia force increases the structural peak acceleration responses, while the increase of horizontal friction force $F_{\text {fh }}$ prevents the structure from returning to its central location and increase the structural residual displacement. The latter also implies that the energy dissipation action is enlarged to decrease the peak relative displacement.
Therefore, the optimum parameters, respectively, aiming at the structural minimum acceleration, minimum relative displacement, and minimum residual displacement, are different. If a structure, such as containing the fragile museum articles, is very sensitive to the acceleration responses, a small friction parameter and a loose spring can be used for the isolation system to reduce the peak acceleration responses [25]. For example, when the parameters adopt $\mu_{0}=0.005, \quad r=0.01 \mathrm{~m}^{-1}, \quad K=100 \mathrm{kN} / \mathrm{m}$, $C=0 \mathrm{kN} \cdot \mathrm{s} / \mathrm{m}, h_{1}=1.0 \mathrm{~m}$, and $h_{0}=0.8 \mathrm{~m}$ in Figures $4(\mathrm{~d})$, $5(\mathrm{~d})$, and $6(\mathrm{~d})$, the probabilities of the structural peak acceleration, peak relative displacement, and residual displacement, exceeding DS1, DS3, and DS3 in Table 2, are $26 \%, 50 \%$, and $60 \%$, respectively. The exceedance probability of structural peak acceleration is very low, while the 

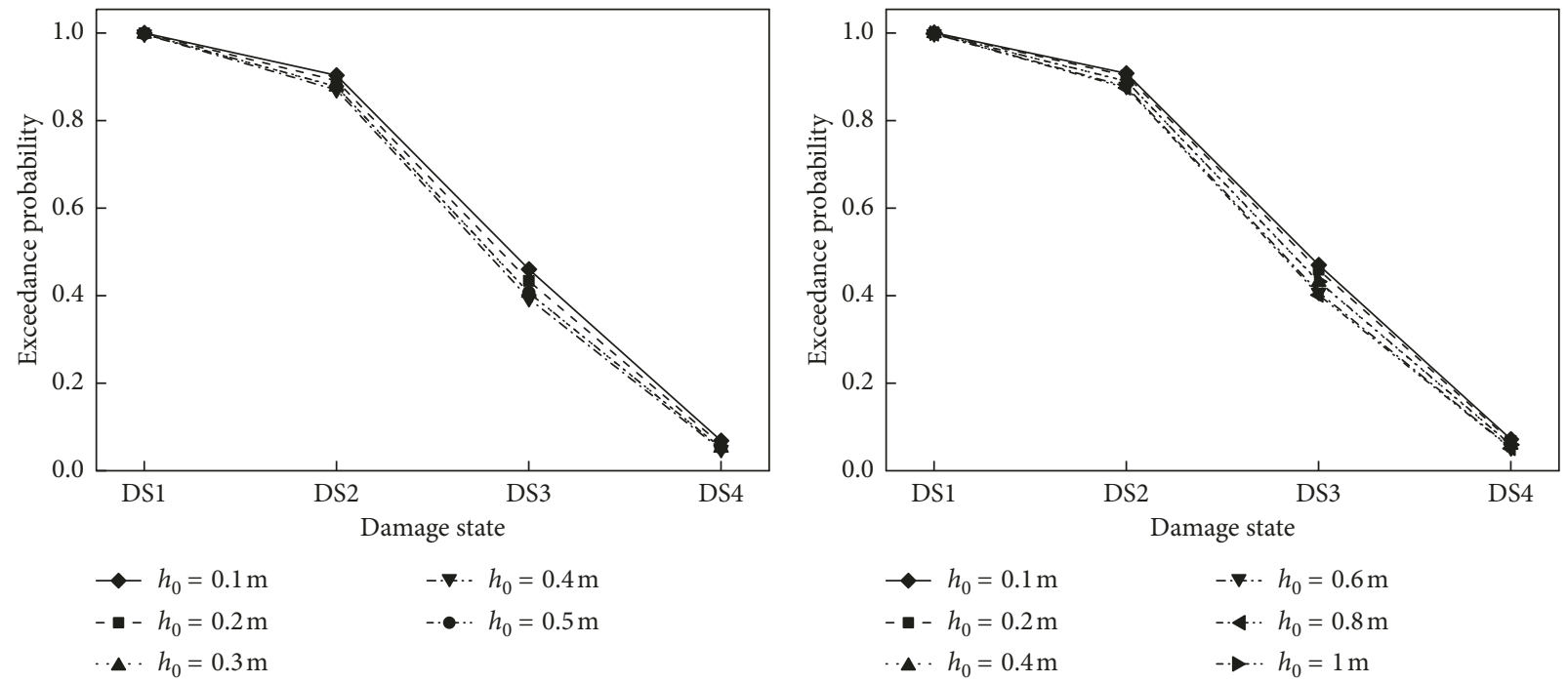

(a)

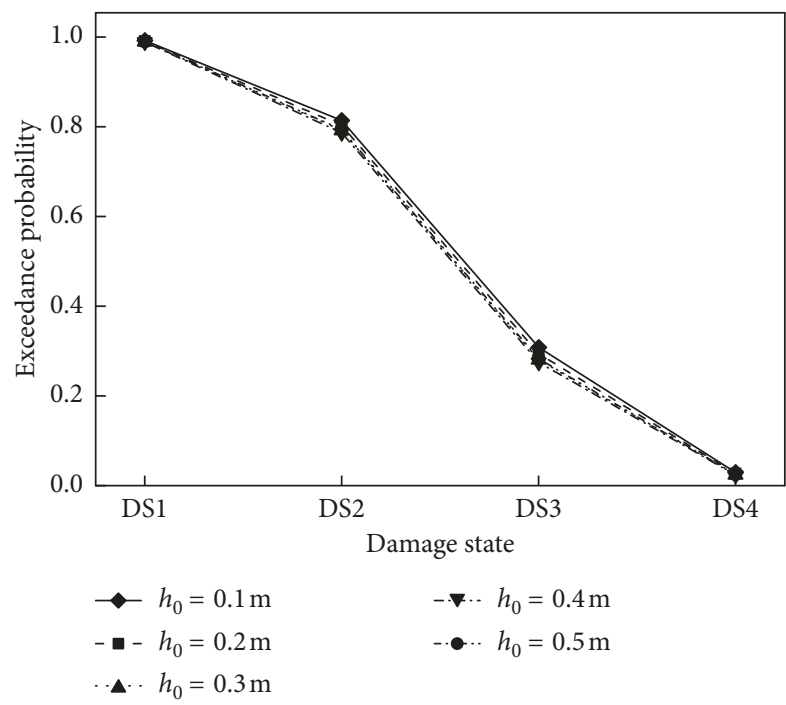

(c)

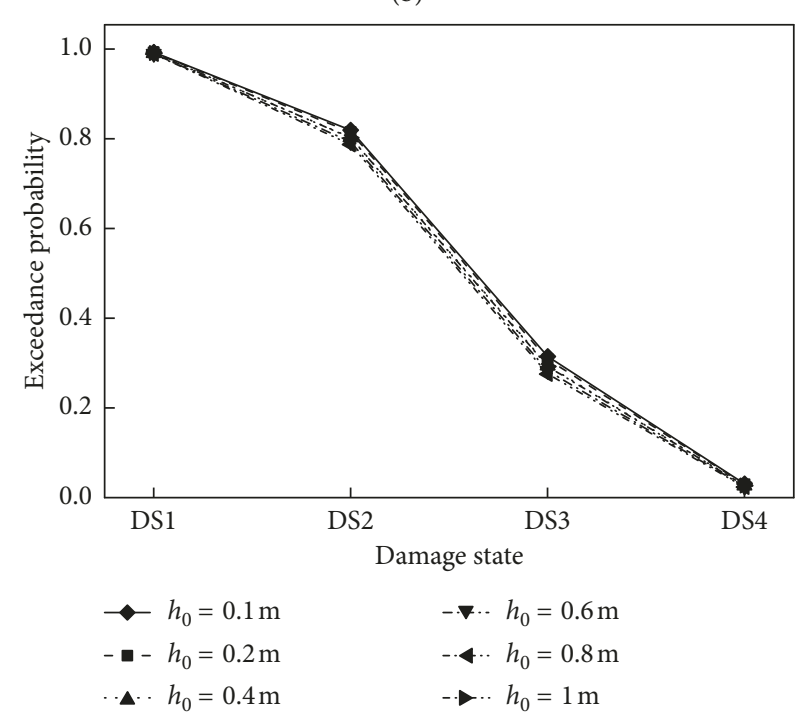

(d)

FIGURE 8: Structural peak relative displacement when $K=100 \mathrm{kN} / \mathrm{m}$ with different damping constant, PGA $=0.8 \mathrm{~g}$ (the horizontal ordinates DS1, DS2, DS3, and DS4 are defined by the structural peak relative displacement in Table 2). (a) $\mu_{0}=0.005, r=0.0 \mathrm{~m}^{-1}, h_{1}=0.5 \mathrm{~m}$, $C=50 \mathrm{kN} \cdot \mathrm{s} / \mathrm{m}$. (b) $\mu_{0}=0.005, r=0.0 \mathrm{~m}^{-1}, h_{1}=1.0 \mathrm{~m}, C=50 \mathrm{kN} \cdot \mathrm{s} / \mathrm{m}$. (c) $\mu_{0}=0.005, r=0.0 \mathrm{~m}^{-1}, h_{1}=0.5 \mathrm{~m}, C=100 \mathrm{kN} \cdot \mathrm{s} / \mathrm{m}$. (d) $\mu_{0}=0.005$, $r=0.0 \mathrm{~m}^{-1}, h_{1}=1.0 \mathrm{~m}, C=100 \mathrm{kN} \cdot \mathrm{s} / \mathrm{m}$.

exceedance probabilities of structural relative displacement and residual displacement have to be high.

6.2. Cases with a Weak Spring and with a Viscous Damper. The influence rules of $h_{0} / h_{1}, h_{1}, \mu_{0}, r$, and other parameters on the structural vulnerability curves in Figures 7-9 are almost the same as those without a viscous damper in Section 6.1; however, they are weakened by adding a viscous damper and increasing the damping constant $C$ in those figures. For example, an increase of the initial spring length $h_{1}$ or the $h_{0} / h_{1}$ decreases the structural peak acceleration, increase the structural residual displacement, and increase or decrease the structural relative displacement, by comparing (a) and (b) in
Figures 7-9. This phenomenon is almost the same as that described in Section 6.1. However, this trend is weakened by comparing (c) and (d) in Figures 7-9, when the damping constant $C$ increases to $100 \mathrm{kN} \cdot \mathrm{s} / \mathrm{m}$.

If a structure, such as containing general articles, is not sensitive to the acceleration responses but sensitive to the displacement responses, a viscous damper with a large damping constant can be used for the isolation system to reduce the structural displacement responses. For example, when the parameters adopt $C=50 \mathrm{kN} \cdot \mathrm{s} / \mathrm{m}, \mu_{0}=0.005$, $r=0.0 \mathrm{~m}^{-1}, K=100 \mathrm{kN} / \mathrm{m}, h_{1}=1.0 \mathrm{~m}$, and $h_{0}=0.8 \mathrm{~m}$ in Figures 7(b), 8(b), and 9(b), the probabilities of the structural peak acceleration, peak relative displacement, and residual displacement, exceeding DS1, DS3, and DS3 in Table 2, are 


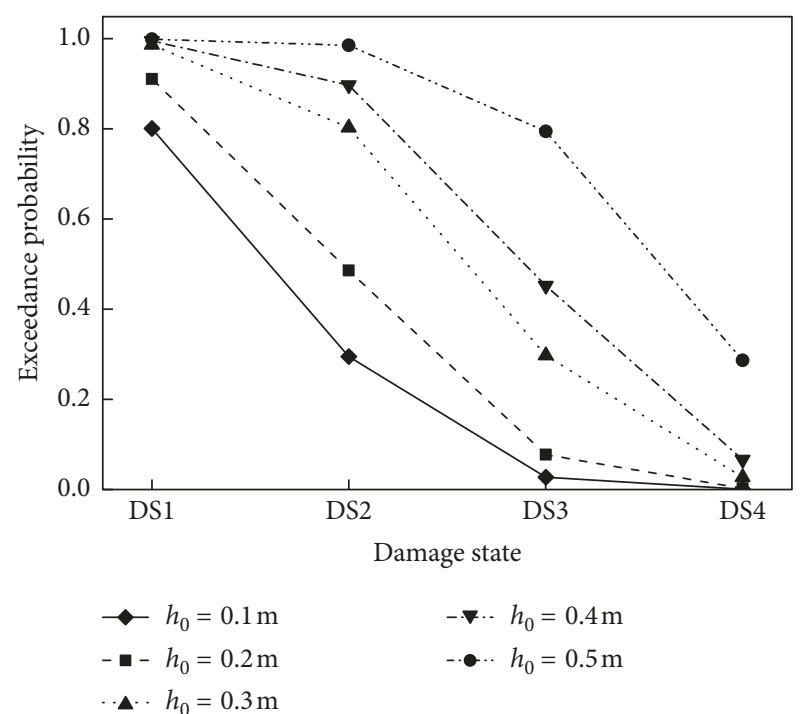

(a)

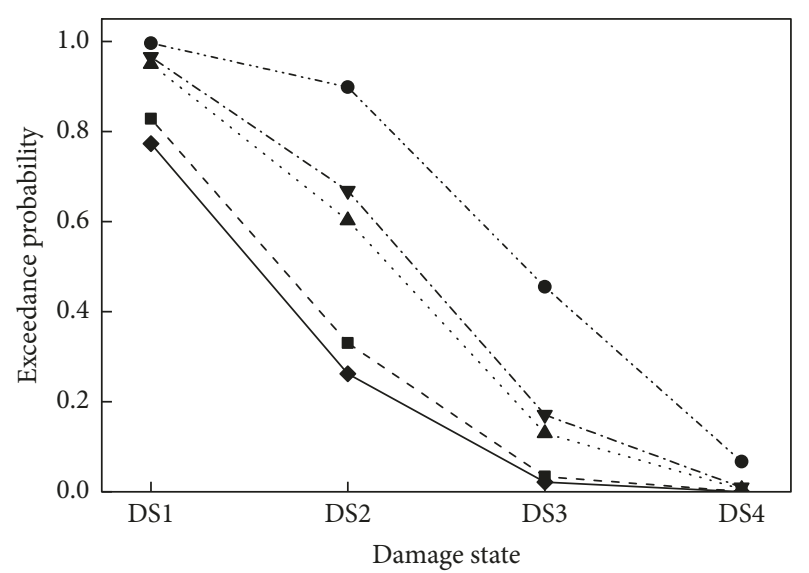

(c)

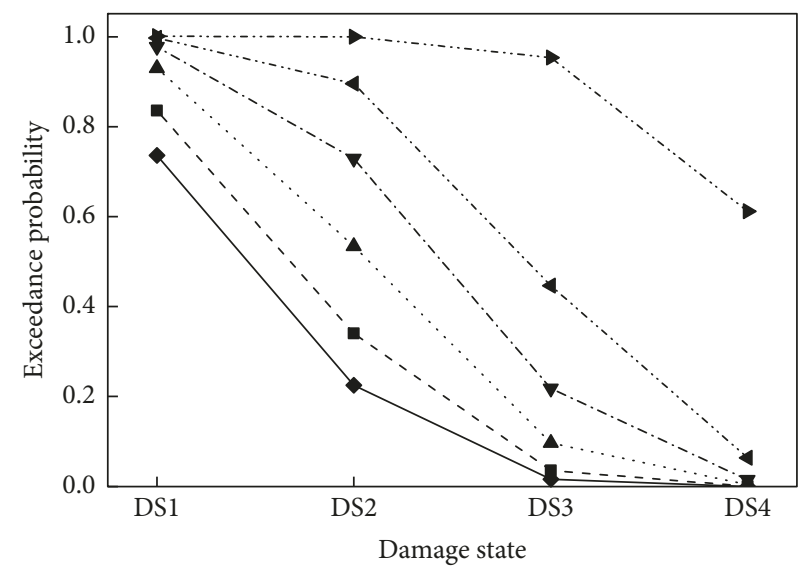

$$
\begin{aligned}
& \longrightarrow h_{0}=0.1 \mathrm{~m} \\
& \text { - } h_{0}=0.2 \mathrm{~m} \\
& \text {... } h_{0}=0.4 \mathrm{~m} \\
& \begin{aligned}
-\cdots & h_{0}=0.6 \mathrm{~m} \\
-\cdots h_{0} & =0.8 \mathrm{~m} \\
\rightarrow \cdots h_{0} & =1 \mathrm{~m}
\end{aligned}
\end{aligned}
$$

(b)

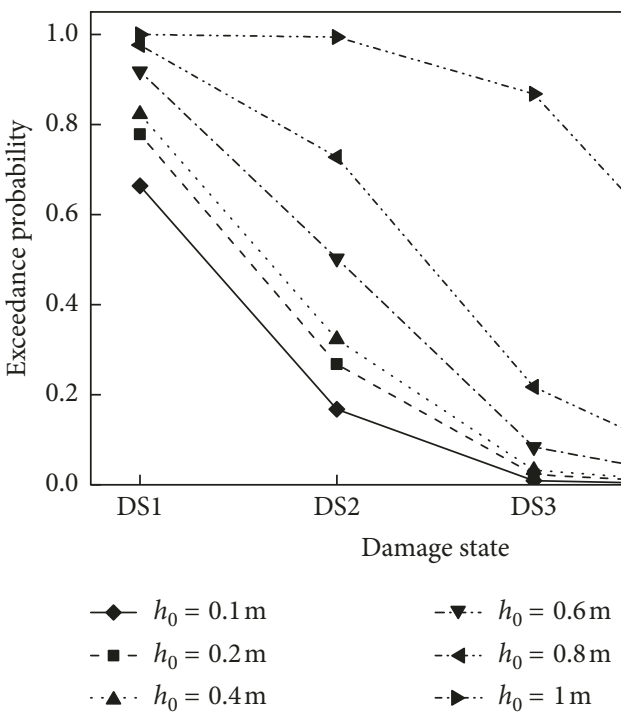

(d)

FIGURE 9: Structural residual displacement when $K=100 \mathrm{kN} / \mathrm{m}$ with different damping constant, PGA $=0.8 \mathrm{~g}$ (the horizontal ordinates DS1, DS2, DS3, and DS4 are defined by the structural residual displacement in Table 2). (a) $\mu_{0}=0.005, r=0.0 \mathrm{~m}^{-1}, h_{1}=0.5 \mathrm{~m}, C=50 \mathrm{kN} \cdot \mathrm{s} / \mathrm{m}$. (b) $\mu_{0}=0.005, r=0.0 \mathrm{~m}^{-1}, h_{1}=1.0 \mathrm{~m}, C=50 \mathrm{kN} \cdot \mathrm{s} / \mathrm{m}$. (c) $\mu_{0}=0.005, r=0.0 \mathrm{~m}^{-1}, h_{1}=0.5 \mathrm{~m}, C=100 \mathrm{kN} \cdot \mathrm{s} / \mathrm{m}$. (d) $\mu_{0}=0.005, r=0.0 \mathrm{~m}{ }^{-1}$, $h_{1}=1.0 \mathrm{~m}, C=100 \mathrm{kN} \cdot \mathrm{s} / \mathrm{m}$.

$33 \%, 40 \%$, and $45 \%$, respectively. It is better than the optimum example without any viscous damper in Section 6.1, except the insignificantly increased acceleration response. Furthermore, when the parameters adopt $C=100 \mathrm{kN} \cdot \mathrm{s} / \mathrm{m}$, $\mu_{0}=0.005, \quad r=0.0 \mathrm{~m}^{-1}, \quad K=100 \mathrm{kN} / \mathrm{m}, \quad h_{1}=1.0 \mathrm{~m}$, and $h_{0}=0.1 \mathrm{~m}$ in Figures $7(\mathrm{~d}), 8(\mathrm{~d})$, and $9(\mathrm{~d})$, the probabilities of the structural peak acceleration, peak relative displacement, and residual displacement, exceeding DS2, DS3, and DS2 in Table 2 , are $26 \%, 31 \%$, and $17 \%$, respectively. The exceedance probabilities of structural displacement decrease, while the exceedance probability of structural acceleration has to increase when the damping constant $C$ increases.
When the damping constant $C$ increases from $0 \mathrm{kN} \cdot \mathrm{s} / \mathrm{m}$ to $50,100,150,200$, and $250 \mathrm{kN} \cdot \mathrm{s} / \mathrm{m}$, the influence degree of $h_{0} / h_{1}, h_{1}, \mu_{0}, r$, and other parameters on the structural vulnerability curves is weakened. The structural displacement responses decrease along with the increasing damping constant $C$. Simultaneously, the structural acceleration response increases for the weak or loose spring cases and insignificantly decreases for the strong or tight spring cases. A too large damping constant $C$ has to be avoided for the isolation system being sensitive to acceleration response, and the according huge and simple vulnerability curves are not listed here. 


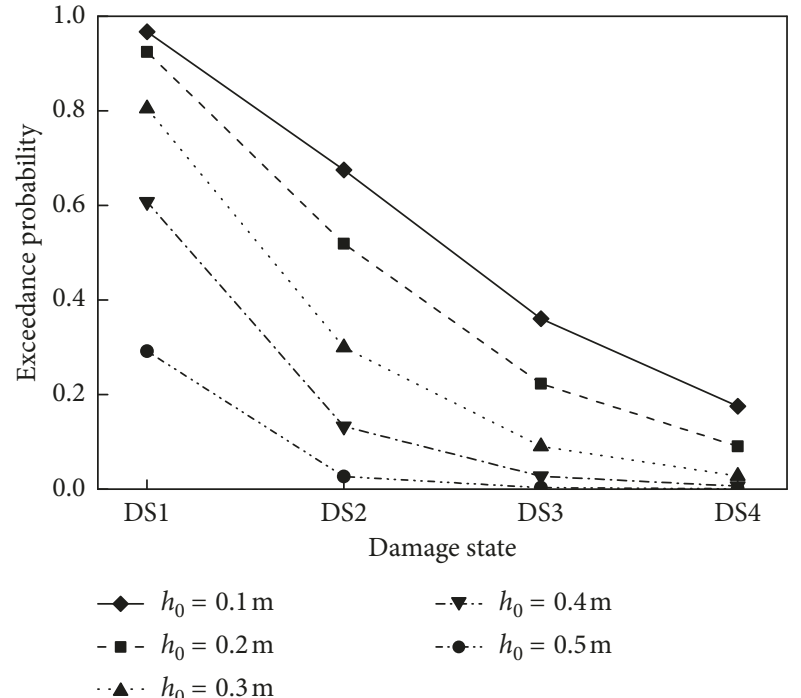

(a)

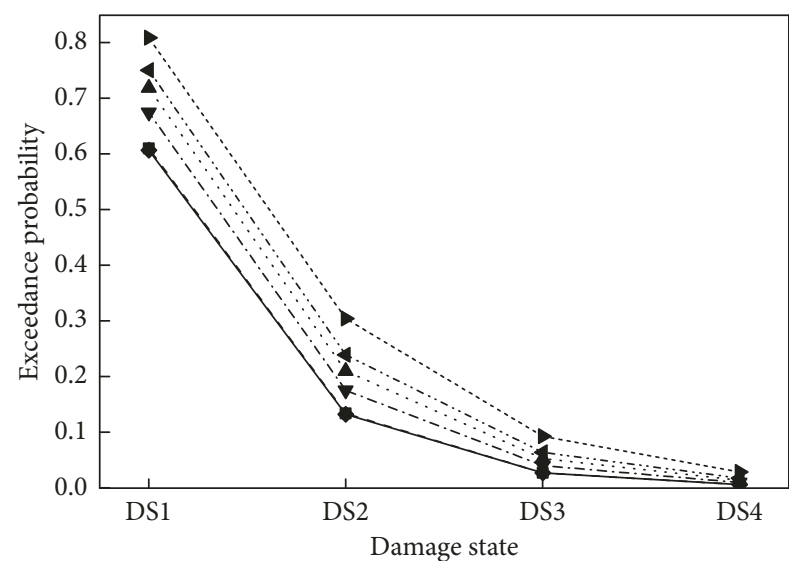

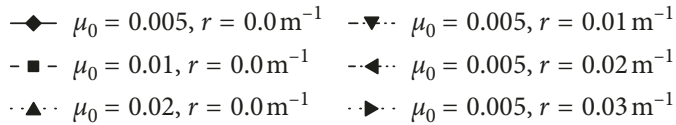

(c)

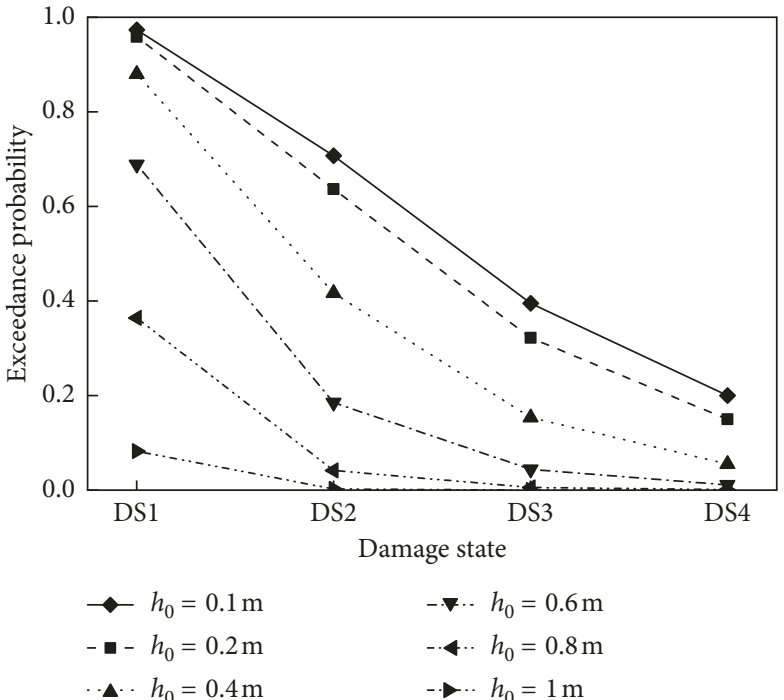

(b)

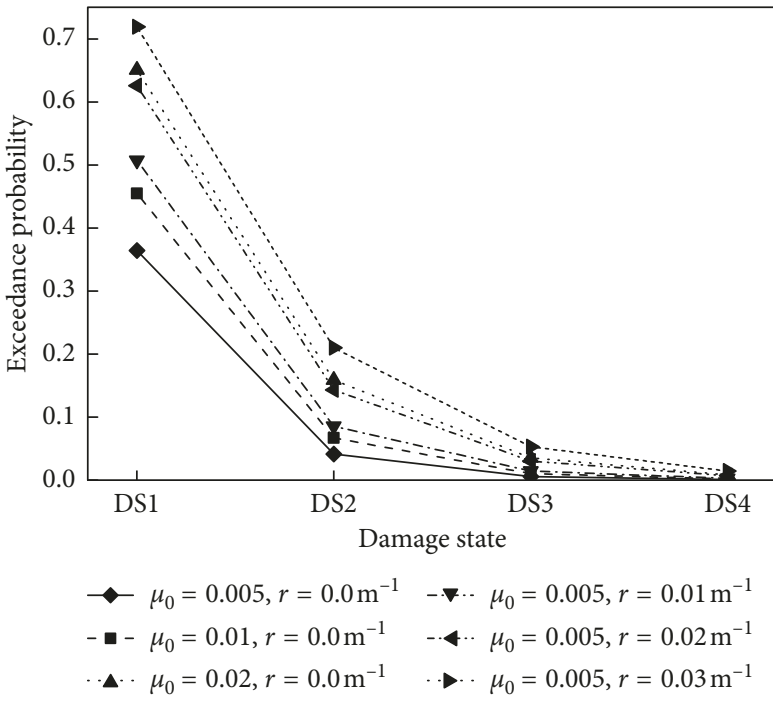

(d)

FIGURE 10: Structural peak acceleration when $K=200 \mathrm{kN} / \mathrm{m}, C=0 \mathrm{kN} \cdot \mathrm{s} / \mathrm{m}$, and PGA $=0.8 \mathrm{~g}$ (the horizontal ordinates DS1, DS2, DS3, and DS4 are defined by the structural peak acceleration in Table 2). (a) $\mu_{0}=0.005, r=0.0 \mathrm{~m}^{-1}, h_{1}=0.5 \mathrm{~m}$. (b) $\mu_{0}=0.005, r=0.0 \mathrm{~m}^{-1}, h_{1}=1.0 \mathrm{~m}$. (c) $h_{1}=0.5 \mathrm{~m}, h_{0}=0.4 \mathrm{~m}$. (d) $h_{1}=1.0 \mathrm{~m}, h_{0}=0.8 \mathrm{~m}$.

6.3. Cases with a Strong Spring. As to compare with the weak spring cases in Section 6.1, the spring constant $\mathrm{K}$ increases from $100 \mathrm{kN} / \mathrm{m}$ to $200 \mathrm{kN} / \mathrm{m}$ in this section by keeping $h_{0} / h_{1}$, $h_{1}, \mu_{0}, r$, and other parameters the same as that in Section 6.1. And the influence rules on the structural vulnerability curves in Figures 10-12 in this section are almost the same as that in Section 6.1.

The increase of spring constant $K$ from $100 \mathrm{kN} / \mathrm{m}$ to $200 \mathrm{kN} / \mathrm{m}$ reduces the structural natural period from being larger than $10 \mathrm{~s}$ to being larger than $7 \mathrm{~s}$ and thus increases the structural inertia force and acceleration response. It is validated by comparing the exceedance probabilities of structural acceleration response in Figures 4 and 10. Simultaneously, the restoring force increases, and thus the structural residual displacement decreases by comparing the exceedance probabilities of DS1, DS2, DS3, and DS4, defined by the structural residual displacement in Table 2, in Figures 6 and 12.

The above increase of spring constant $K$ causes a complex change of structural relative displacement response by comparing the exceedance probabilities in Figures 5 and 11 as follows:

(1) As for the cases with a small friction coefficient $\mu_{0}$ and a small increment ratio $r$ of the concave friction distribution, the structural peak relative displacement increases along with the increasing $K$ except some loose spring cases 


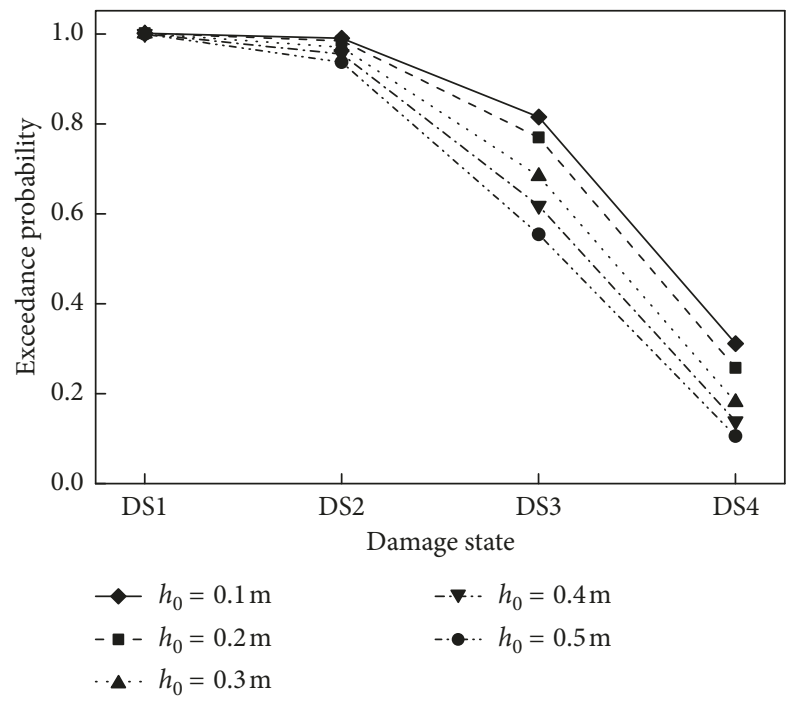

(a)

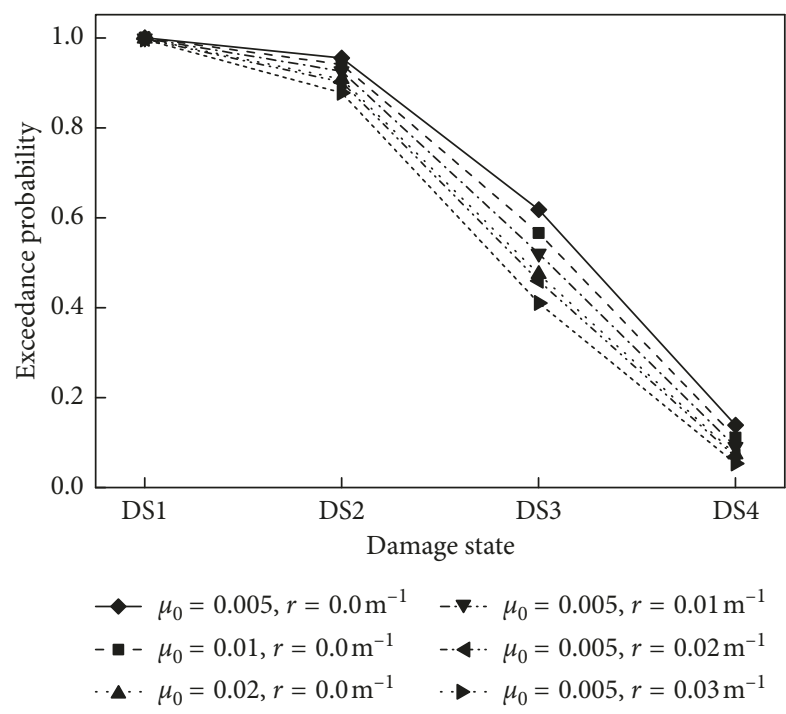

(c)

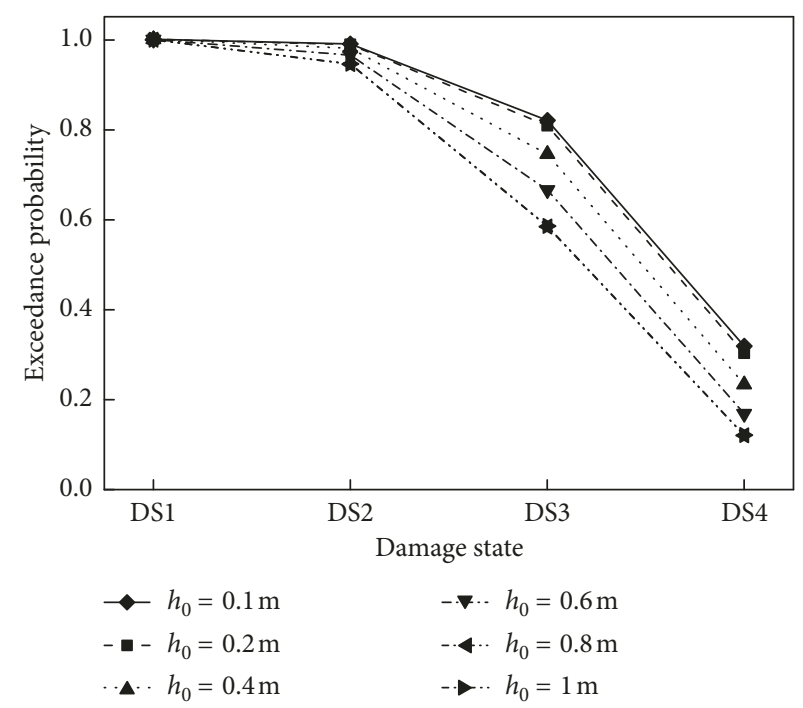

(b)

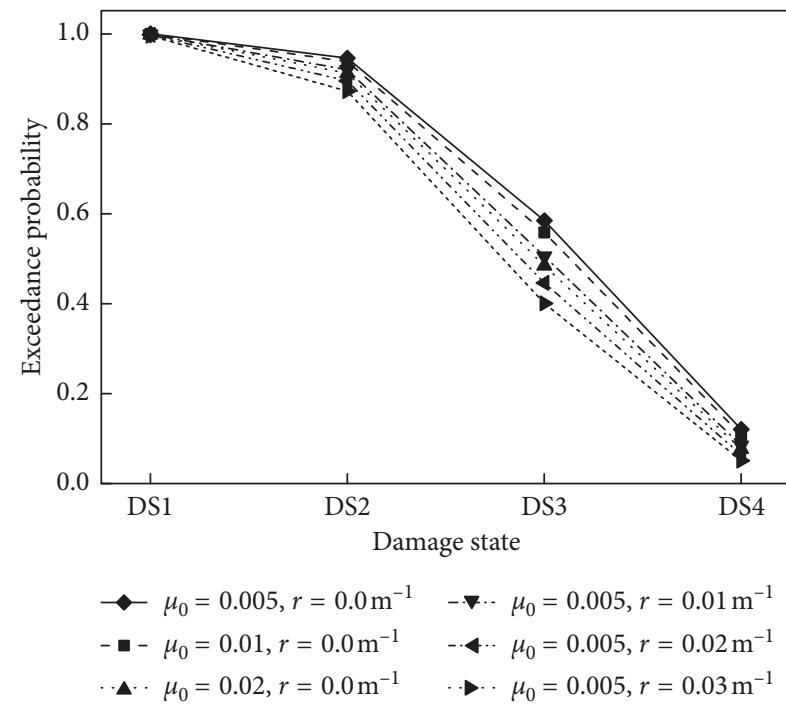

(d)

FIGURE 11: Structural peak relative displacement when $K=200 \mathrm{kN} / \mathrm{m}, C=0 \mathrm{kN} \cdot \mathrm{s} / \mathrm{m}$, and PGA $=0.8 \mathrm{~g}$ (the horizontal ordinates DS1, DS2, DS3, and DS4 are defined by the structural peak relative displacement in Table 2). (a) $\mu_{0}=0.005, r=0.0 \mathrm{~m}^{-1}, h_{1}=0.5 \mathrm{~m}$. (b) $\mu_{0}=0.005$, $r=0.0 \mathrm{~m}^{-1}, h_{1}=1.0 \mathrm{~m}$. (c) $h_{1}=0.5 \mathrm{~m}, h_{0}=0.4 \mathrm{~m}$. (d) $h_{1}=1.0 \mathrm{~m}, h_{0}=0.8 \mathrm{~m}$.

(2) In terms of the cases with a large friction coefficient $\mu_{0}$, the structural peak relative displacement decreases along with the increasing $K$

(3) When the cases with a small $\mu_{0}$ and a large $r$ is concerned, the structural peak relative displacement increases along with the increasing $K$ except some loose spring cases

The above phenomena implies that the friction action can cause the instantaneous natural period of structure to be close to or far away from a certain long period component of earthquakes.

When the spring constant $K$ continuously increases to $300,400,500$, and $600 \mathrm{kN} / \mathrm{m}$, the structural natural period will decrease to being larger than $6,5,4.8$, and $4.4 \mathrm{~s}$, respectively. Those periods tend to be closer to the main period components of earthquakes and thus increase the structural peak acceleration response. A large spring constant $K$ has to be avoided for the structure being sensitive to acceleration response, and the according huge and simple vulnerability curves are not listed here.

\section{Further Optimization of Isolation System}

Based on the above parameter analysis and discussion, the vertical spring-viscous damper-Coulomb friction isolation system has a lot of merits during earthquakes as follows:

(1) When the structural relative displacement $d_{\mathrm{r}}=0$, the horizontal component of spring force is 0 and 

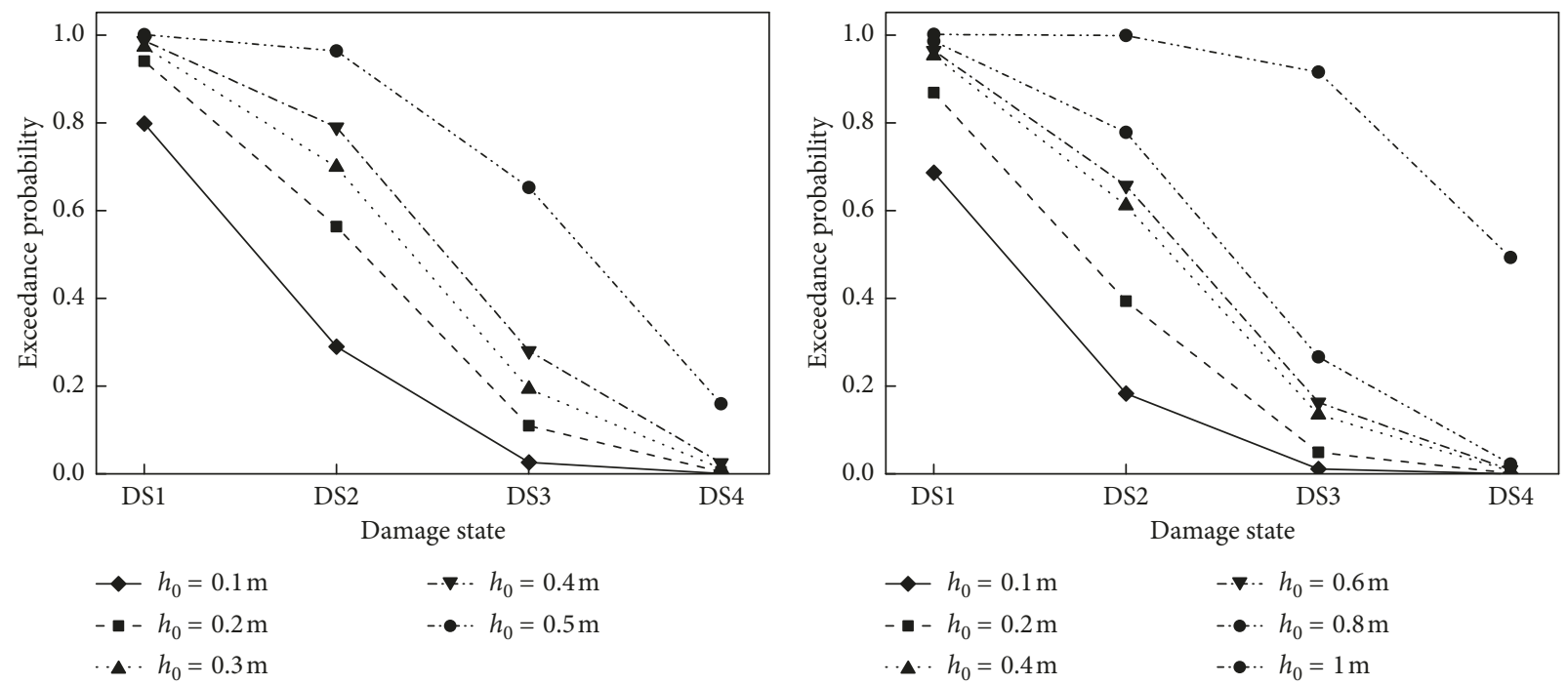

(a)

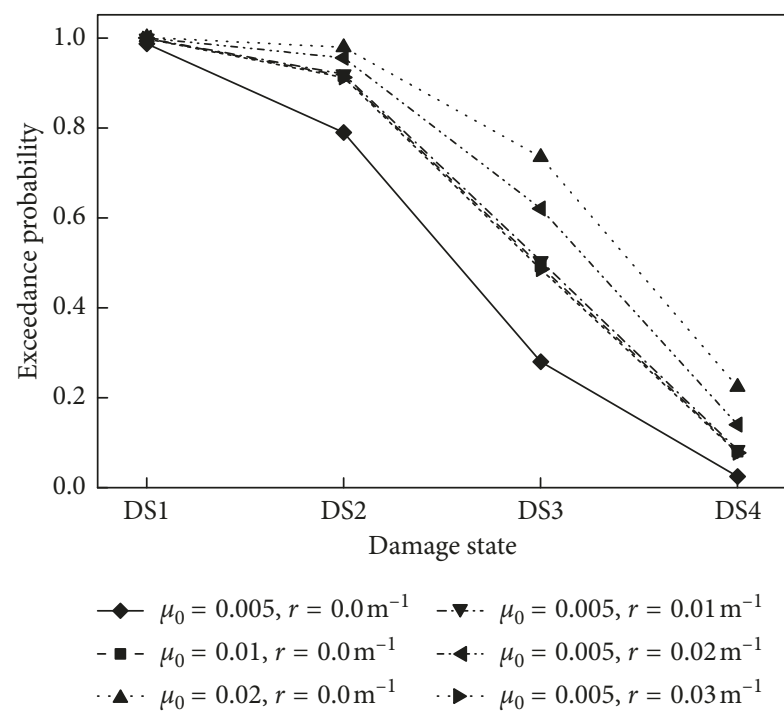

(b)

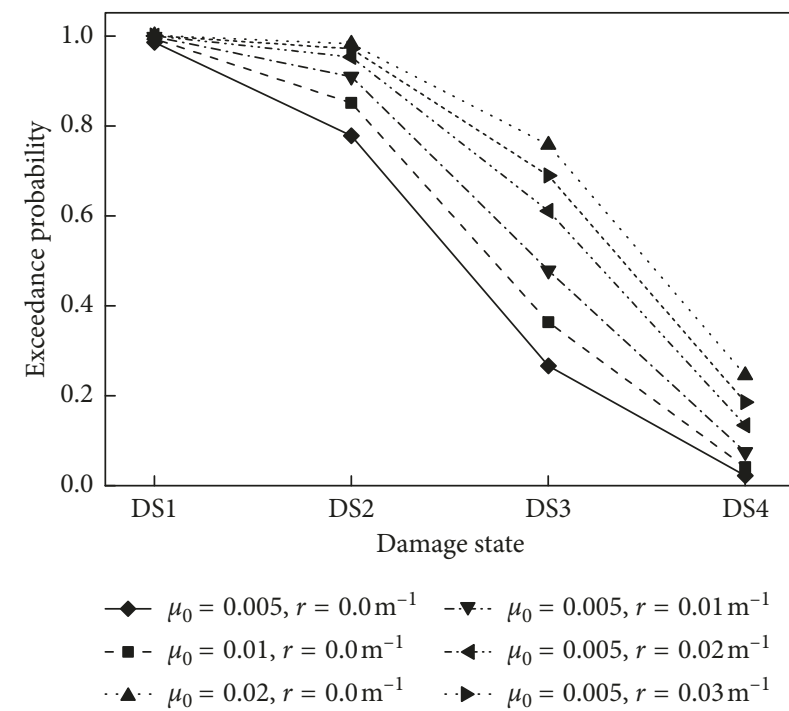

(d)

Figure 12: Structural residual displacement when $K=200 \mathrm{kN} / \mathrm{m}, C=0 \mathrm{kN} \cdot \mathrm{s} / \mathrm{m}$, and PGA $=0.8 \mathrm{~g}$ (the horizontal ordinate DS1, DS2, DS3, and DS4 are defined by the structural residual displacement in Table 2). (a) $\mu_{0}=0.005, r=0.0 \mathrm{~m}^{-1}, h_{1}=0.5 \mathrm{~m}$. (b) $\mu_{0}=0.005, r=0.0 \mathrm{~m}^{-1}$, $h_{1}=1.0 \mathrm{~m}$. (c) $h_{1}=0.5 \mathrm{~m}, h_{0}=0.4 \mathrm{~m}$. (d) $h_{1}=1.0 \mathrm{~m}, h_{0}=0.8 \mathrm{~m}$.

the friction force is so small due to the concave friction pattern that they insignificantly disturb the cutting off of shear key used for service loadings.

(2) The loose spring and the viscous damper with a small damping constant can be used to reduce the structural acceleration response. And the variable horizontal component of spring stiffness along with the structural relative displacement can avoid resonance.

(3) The friction force on the concave friction contact surface increases along with the structural relative displacement to increase the dissipation capacity of energy [41], and thus to reduce the relative displacement response.
(4) The vertical component of spring force is controlled to avoid the interfacial detachment between the structure and the ground and is enlarged to increase the above friction force along with the structural relative displacement.

Therefore, when the parameters adopt $\mu_{0}=0.005$, $r=0.01 \mathrm{~m}^{-1}, K=100 \mathrm{kN} / \mathrm{m}, C=0 \mathrm{kN} \cdot \mathrm{s} / \mathrm{m}, h_{1}=1.0 \mathrm{~m}$, and $h_{0}=0.8 \mathrm{~m}$ in Figures 4(d), 5(d), and 6(d), the probabilities of the structural peak acceleration, peak relative displacement, and residual displacement, exceeding DS1, DS3, and DS3 in Table 2, are 26\%, 50\%, and 60\%, respectively. It may be a good isolation project; however, it can be further improved by using the advanced technique in the friction region as follows: 


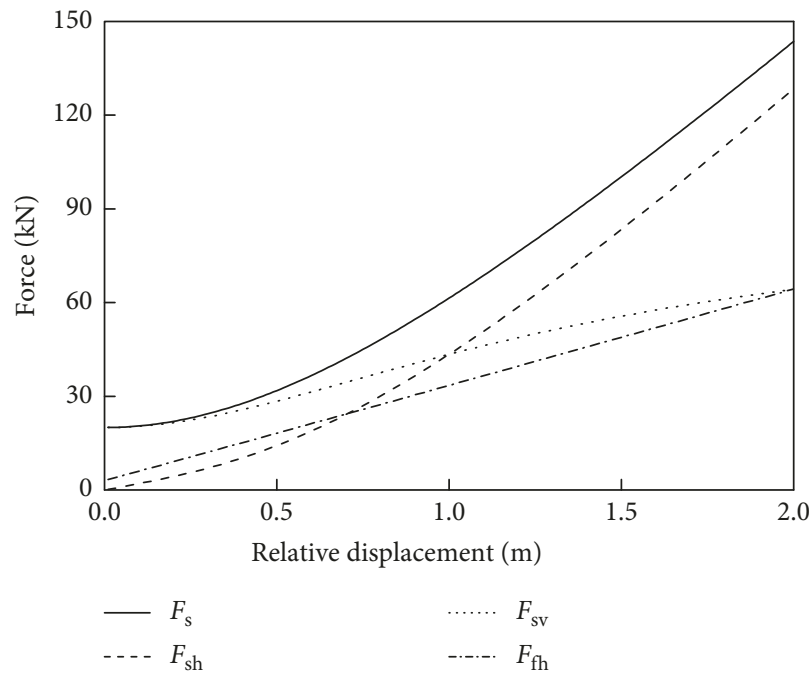

(a)

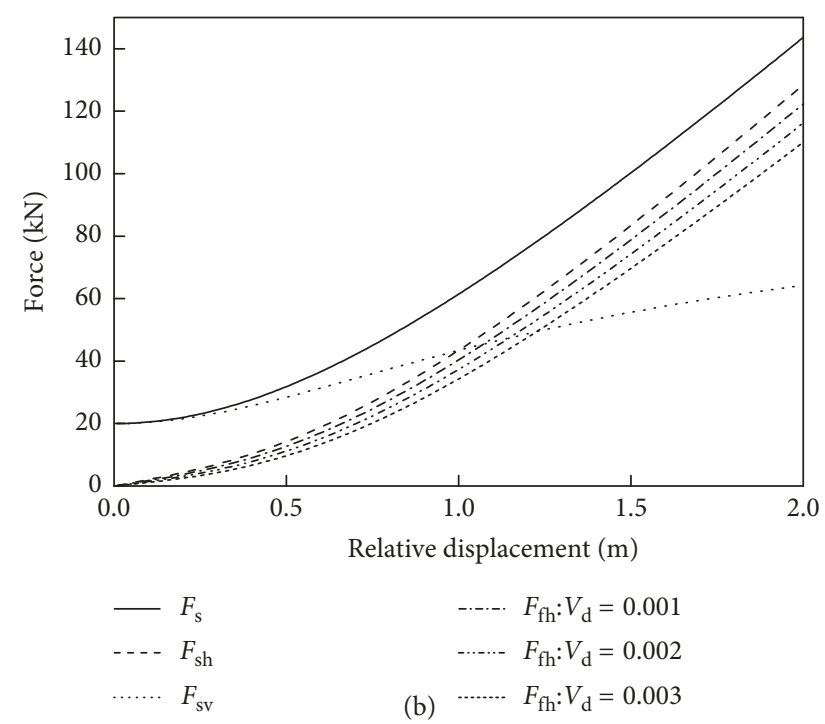

FIGURE 13: Force-displacement relationship when $K=100 \mathrm{kN} / \mathrm{m}, h_{1}=1.0 \mathrm{~m}$ and $h_{0}=0.8 \mathrm{~m}$. (a) $\mu_{0}=0.005, r=0.01 \mathrm{~m}^{-1}$. (b) $\mu_{0}=0.001$ and $r$ is variable.

(1) As to further decrease the structural residual displacement, the central friction coefficient $\mu_{0}$ of contact surface can be further reduced from $\mu_{0}=0.005$ in Figure 13 (a) to $\mu_{0}=0.001$ in Figure 13(b) by using the super lubrication technique.

(2) If the increment ratio $r$ of concave friction distribution adopts a constant value such as $r=0.01 \mathrm{~m}^{-1}$, the friction force will be larger than the horizontal component of spring force within a certain relative displacement in Figure 13(a), and thus the structural residual displacement is always large after earthquakes. If $r$ is changed from a constant value to a variable value, the friction force can be controlled to be always less than the horizontal component of spring force within any relative displacement in Figure 13(b). Such a variable $r$ can be derived from $F_{\text {sh }}=F_{\text {fh }}$ in equations (2) and (7):

$$
r=\frac{K\left(\sqrt{h_{1}^{2}+d_{\mathrm{r}}^{2}}-h_{0}\right)\left(d_{\mathrm{r}}-\mu_{0} h_{1}\right)-\mu_{0} m g \sqrt{h_{1}^{2}+d_{\mathrm{r}}^{2}}}{d_{\mathrm{r}}\left[m g \sqrt{h_{1}^{2}+d_{\mathrm{r}}^{2}}+K\left(\sqrt{h_{1}^{2}+d_{\mathrm{r}}^{2}}-h_{0}\right) h_{1}\right]} .
$$

The above equation (8) can achieve $F_{\text {sh }}=F_{\text {fh }}$. As to achieve $F_{\text {sh }}>F_{\text {fh }}$, however, a small artificial constant parameter $V_{\mathrm{d}}$, such as $0.001,0.002$, and $0.003 \mathrm{~m}^{-1}$, is added to equation (8) to get a new equation (9). Equations (8) and (9) are firstly proposed in this paper.

$$
r=\frac{K\left(\sqrt{h_{1}^{2}+d_{\mathrm{r}}^{2}}-h_{0}\right)\left(d_{\mathrm{r}}-\mu_{0} h_{1}\right)-\mu_{0} m g \sqrt{h_{1}^{2}+d_{\mathrm{r}}^{2}}}{d_{\mathrm{r}}\left[m g \sqrt{h_{1}^{2}+d_{\mathrm{r}}^{2}}+K\left(\sqrt{h_{1}^{2}+d_{\mathrm{r}}^{2}}-h_{0}\right) h_{1}\right]}-V_{\mathrm{d}} .
$$

When the parameters in Figure 13(b) are used, the curve fitting probabilities [40] of the structural peak acceleration and peak relative displacement, exceeding different damage states in Table 2, are shown in Figures 14 and 15, respectively. If a viscous damper with a small damping constant $C=10 \mathrm{kN} \cdot \mathrm{s} / \mathrm{m}$ is added to the case with $\mu_{0}=0.001$, $V_{\mathrm{d}}=0.003 \mathrm{~m}^{-1}, K=100 \mathrm{kN} / \mathrm{m}, h_{1}=1.0 \mathrm{~m}$, and $h_{0}=0.8 \mathrm{~m}$, the corresponding results are shown in Figures $14(\mathrm{~d})$ and 15(d). Furthermore, the exceedance probabilities of DS1, DS2, DS3, and DS4, defined by the structural residual displacement in Table 2, are always 0 due to $F_{\text {sh }}>F_{\text {fh }}$, and are not listed here.

The exceedance probabilities of DS1, DS2, DS3, and DS4, defined by the structural peak acceleration and peak relative displacement in Table 2, increase with PGA in Figures 14 and 15. When $V_{\mathrm{d}}=0.001,0.002$, and $0.003 \mathrm{~m}^{-1}$ and $C=0 \mathrm{kN} \cdot \mathrm{s} / \mathrm{m}$ and $V_{\mathrm{d}}=0.003 \mathrm{~m}^{-1}$ and $C=10 \mathrm{kN} \cdot \mathrm{s} / \mathrm{m}$ under the earthquakes with $\mathrm{PGA}=0.8 \mathrm{~g}$, the probabilities of the structural peak acceleration, exceeding DS1 in Table 2, are 12.3\%, 10.7\%, 9.2\%, and $10.1 \%$, respectively. The corresponding probabilities of the structural peak relative displacement, exceeding DS3 in Table 2 , are $40.6 \%, 41.4 \%, 42.2 \%$, and $39.6 \%$, respectively. Those exceedance probabilities of structural peak acceleration decrease while those exceedance probabilities of structural peak relative displacement increase when $V_{\mathrm{d}}$ increases. The adding of the viscous damper with a small damping constant $C=10 \mathrm{kN} \cdot \mathrm{s} / \mathrm{m}$ can decrease the structural peak relative displacement but increase the structural peak acceleration. All of the above exceedance probabilities are much less than the results of the case adopting $\mu_{0}=0.005, r=0.01 \mathrm{~m}^{-1}$, $K=100 \mathrm{kN} / \mathrm{m}, C=0 \mathrm{kN} \cdot \mathrm{s} / \mathrm{m}, h_{1}=1.0 \mathrm{~m}$, and $h_{0}=0.8 \mathrm{~m}$ in Figures 4(d), 5(d), and 6(d). Importantly, the isolation system in this section does not need repair except the installation of 


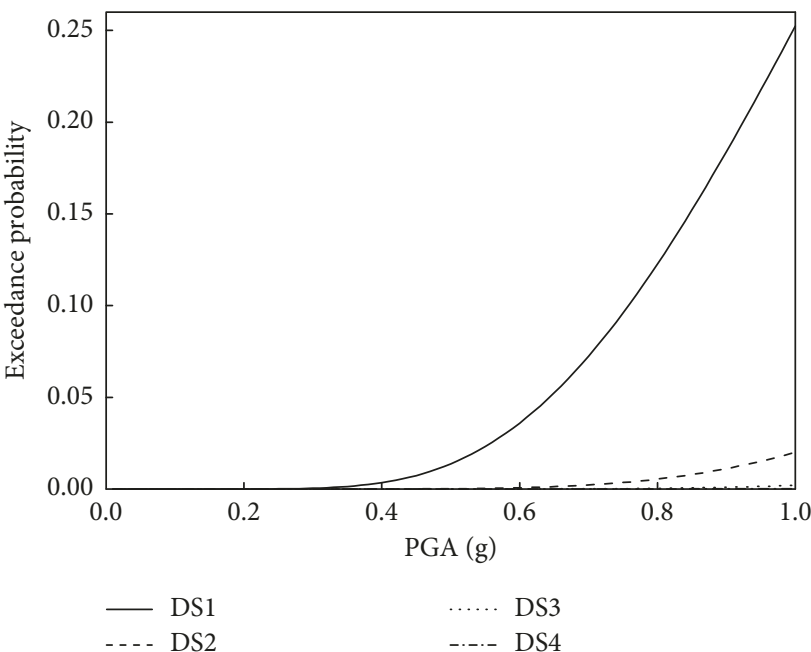

(a)

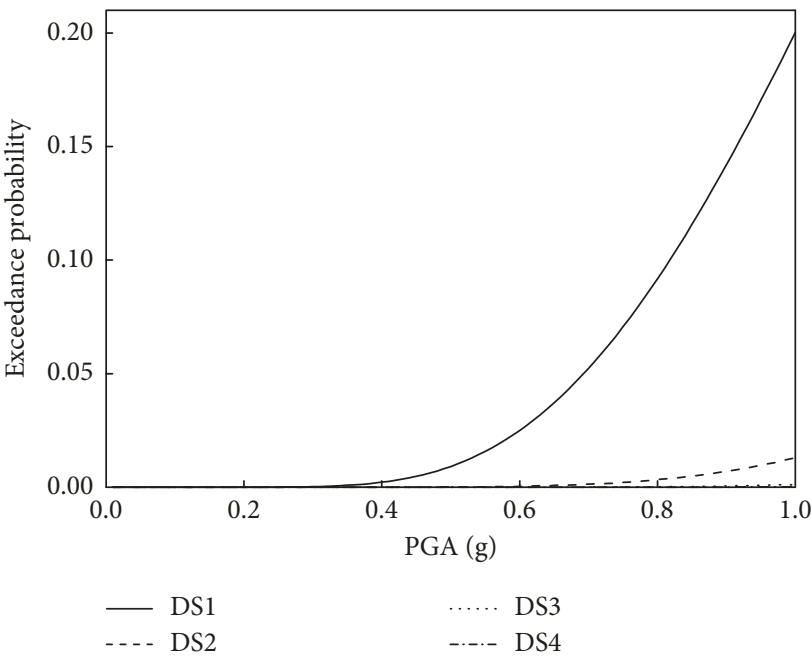

(c)

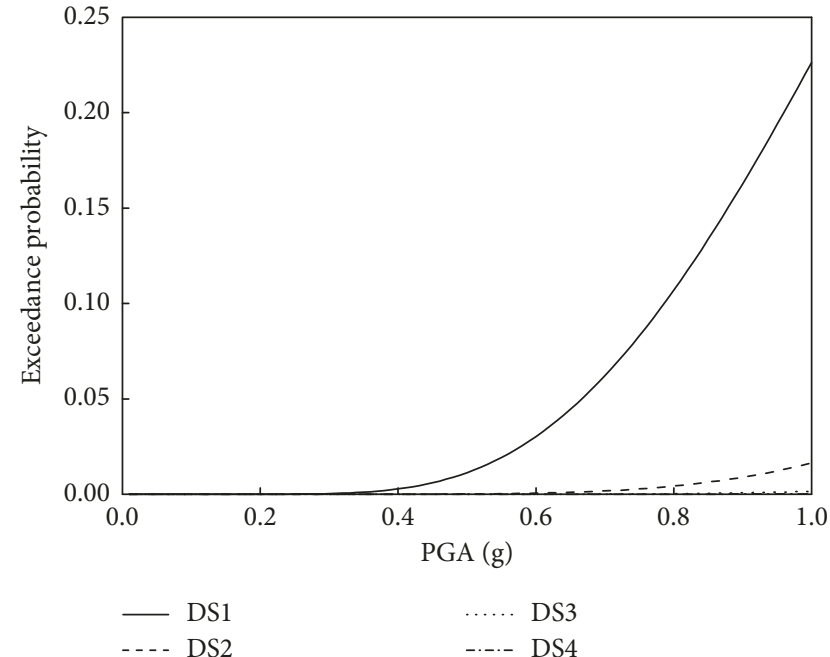

(b)

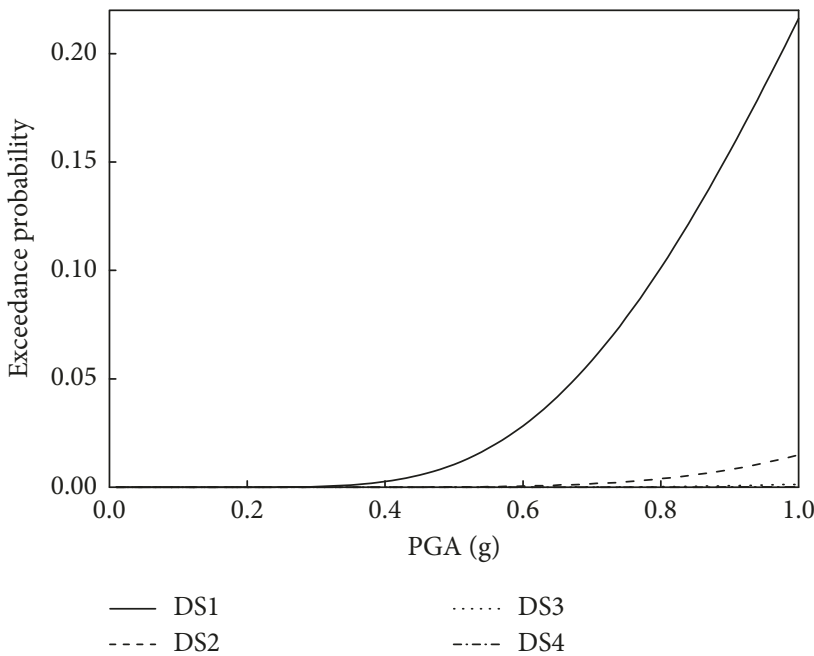

(d)

FIGURE 14: Structural peak acceleration when $\mu_{0}=0.001, K=100 \mathrm{kN} / \mathrm{m}, h_{1}=1.0 \mathrm{~m}$, and $h_{0}=0.8 \mathrm{~m}$ (DS1, DS2, DS3, and DS4 are defined by the structural peak acceleration in Table 2). (a) $V_{\mathrm{d}}=0.001 \mathrm{~m}^{-1}$ and $C=0 \mathrm{kN} \cdot \mathrm{s} / \mathrm{m}$. (b) $V_{\mathrm{d}}=0.002 \mathrm{~m}^{-1}$ and $C=0 \mathrm{kN} \cdot \mathrm{s} / \mathrm{m}$. (c) $V_{\mathrm{d}}=0.003 \mathrm{~m}-1$ and $C=0 \mathrm{kN} \cdot \mathrm{s} / \mathrm{m}$. (d) $V_{\mathrm{d}}=0.003 \mathrm{~m}^{-1}$ and $C=10 \mathrm{kN} \cdot \mathrm{s} / \mathrm{m}$.

new shear key after earthquakes since the structural residual displacement is always 0 .

\section{Conclusions}

This paper investigates the seismic isolation efficiency of a vertical spring-viscous damper-Coulomb friction system and analyzes the influence of concave friction distribution, damping constant, spring constant, and spring tightness on the isolation performance. The different combinations of those influence factors result in different seismic isolation performance. And different optimal parameters of those influence factors can be selected for the structures with different functions by the performance-based earthquake engineering principles.

The structural residual displacement can be absolutely avoided by using a super lubrication in the middle of contact surface and a variable increment ratio of concave friction distribution in equation (9). In this way, the friction force is always less than the horizontal component of spring force within any relative displacement during earthquakes.

The contradictions between the structural peak acceleration and peak relative displacement seem to be irreconcilable. One is reduced while the other is increased when selecting the structural optimal parameters.

If the structure, such as a building containing the fragile museum articles, is very sensitive to the acceleration response, a low friction parameter, a small spring constant, and a small and even zero damping constant could be adopted to yield a small peak acceleration of system. The tightness of vertical spring can be adjusted by increasing $h_{0} / h_{1}$ and $h_{1}$ to be appropriately loose to continuously reduce the structural acceleration response. However, the relative displacement response will be large for the soft 


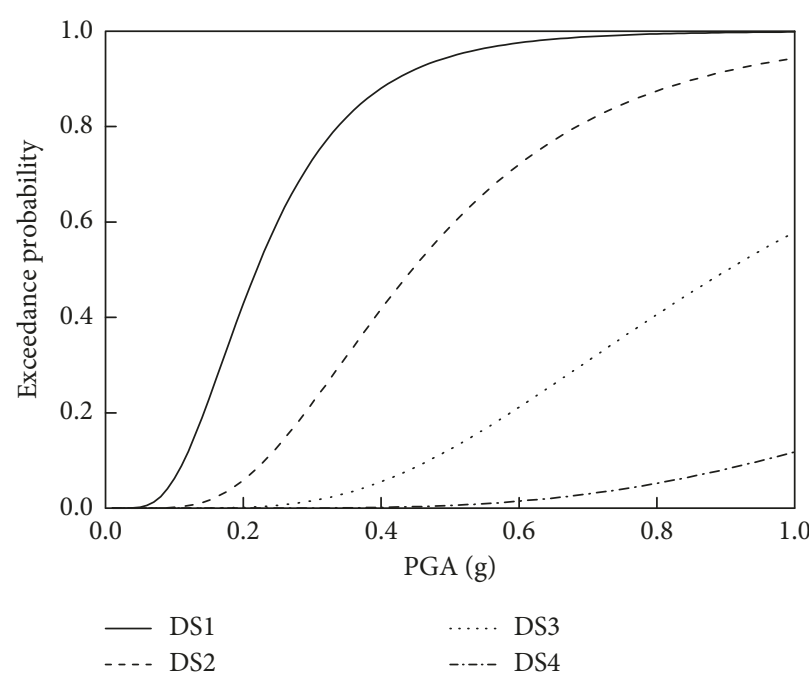

(a)

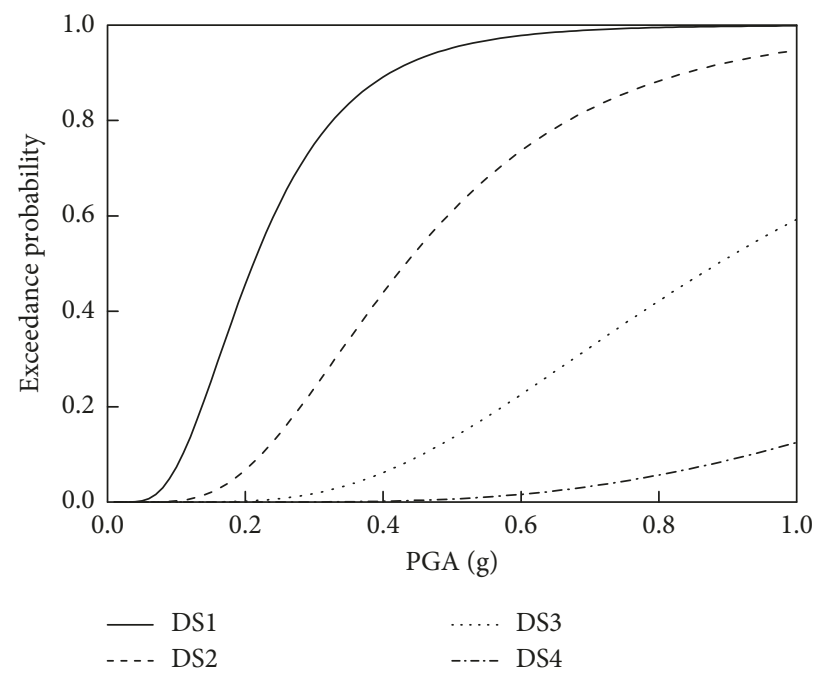

(c)

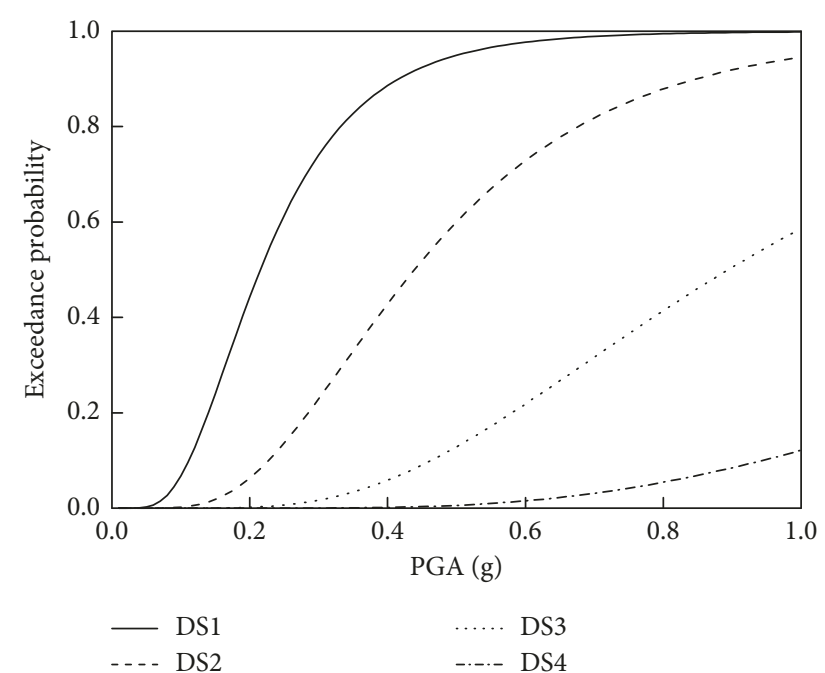

(b)

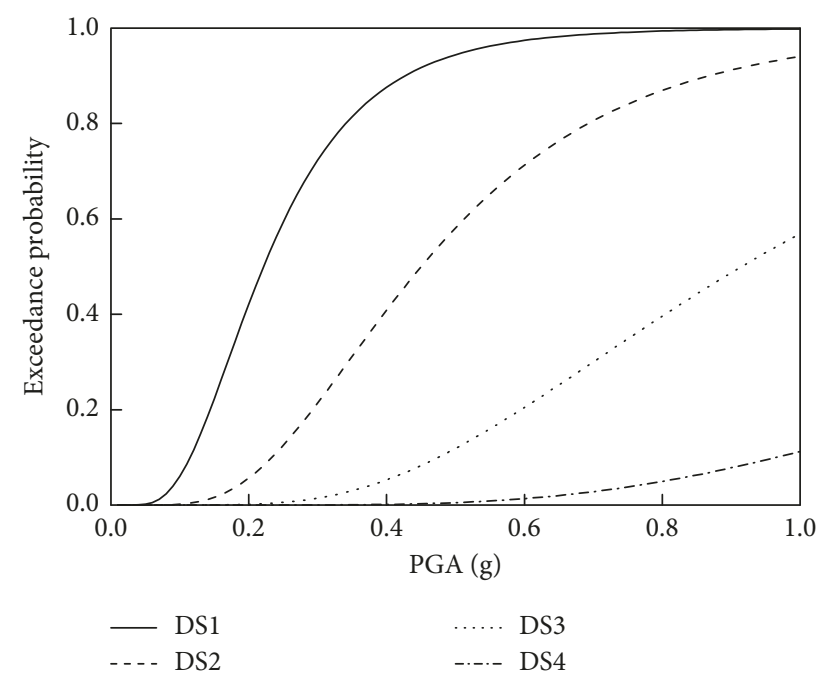

(d)

Figure 15: Structural peak relative displacement when $\mu_{0}=0.001, K=100 \mathrm{kN} / \mathrm{m}, h_{1}=1.0 \mathrm{~m}$, and $h_{0}=0.8 \mathrm{~m}$ (DS1, DS2, DS3, and DS4 are defined by the structural peak relative displacement in Table 2). (a) $V_{\mathrm{d}}=0.001 \mathrm{~m}^{-1}$ and $C=0 \mathrm{kN} \cdot \mathrm{s} / \mathrm{m}$. (b) $V_{\mathrm{d}}=0.002 \mathrm{~m}^{-1}$ and $C=0 \mathrm{kN} \cdot \mathrm{s} / \mathrm{m}$. (c) $V_{\mathrm{d}}=0.003 \mathrm{~m}^{-1}$ and $C=0 \mathrm{kN} \cdot \mathrm{s} / \mathrm{m}$. (d) $V_{\mathrm{d}}=0.003 \mathrm{~m}^{-1}$ and $C=10 \mathrm{kN} \cdot \mathrm{s} / \mathrm{m}$.

system. Fortunately, the increased horizontal stiffness and spring force due to the relative motion will avoid a too large relative displacement of system.

If the structure, such as a building containing the general articles, is not very sensitive to the acceleration response, more optimal parameters can be selected for the isolation system. For example, the tightness of vertical spring can be adjusted by reducing $h_{0} / h_{1}$ and $h_{1}$ to be appropriately tight to increase the structural peak acceleration; however, it can reduce the structural displacement response efficiently. And the displacement response can be further reduced by adding a viscous damper with an appropriate damping constant to or increasing the friction parameter in the isolation system.

In theory, the seismic isolation of the buildings, the bridges, the railways, and other structures can be improved by using the method in this paper. Using equation (9) can ensure there is not any residual displacement or any severe repair for these structures after earthquakes. And the above parameters can be adjusted to balance the structural acceleration responses and the structural relative displacement responses. However, the method in this paper is derived only based on a sensitivity analysis of a single degree of freedom (SDOF) system. And a wide validation, using the finite element model analysis, needs further investigation when the method is applied to the different types of specific multidegree of freedom (MDOF) structures $[42,43]$ in the future.

\section{Data Availability}

The data used to support the findings of this study are included within the article. The data include the structural parameters, ground motion inputs, calculation methods, and calculation results. 


\section{Conflicts of Interest}

The authors declare that they have no conflicts of interest.

\section{Acknowledgments}

This research was jointly supported by the National Key R\&D Program of China under grant no. 2017YFB1201204, the Natural Science Foundation of Hunan Province under grant no. 2019JJ40386, the Research Program on Displacement Limitation Technology of Half-Through Railway Arch Bridge under grant no. science2018-81, and the Science and Technology Project of Sichuan Province under grant no. 2019YFG0048. The above support is greatly appreciated.

\section{References}

[1] M. Ismail, J. Rodellar, and F. Pozo, "Passive and hybrid mitigation of potential near-fault inner pounding of a selfbraking seismic isolator," Soil Dynamics and Earthquake Engineering, vol. 69, no. 2, pp. 233-250, 2015.

[2] D. M. Siringoringo and Y. Fujino, "Seismic response analyses of an asymmetric base-isolated building during the 2011 Great East Japan (Tohoku) Earthquake," Structural Control and Health Monitoring, vol. 22, no. 1, pp. 71-90, 2015.

[3] P. S. Harvey and H. P. Gavin, "The nonholonomic and chaotic nature of a rolling isolation system," Journal of Sound and Vibration, vol. 332, no. 14, pp. 3535-3551, 2013.

[4] P. S. Harvey, R. Wiebe, and H. P. Gavin, "On the chaotic response of a nonlinear rolling isolation system," Physica $D$ : Nonlinear Phenomena, vol. 256-257, no. 8, pp. 36-42, 2013.

[5] P. S. Harvey and H. P. Gavin, "Double rolling isolation systems: a mathematical model and experimental validation," International Journal of Non-Linear Mechanics, vol. 61, no. 1, pp. 80-92, 2014.

[6] P. S. Harvey, G.-P. Zéhil, and H. P. Gavin, "Experimental validation of a simplified model for rolling isolation systems," Earthquake Engineering \& Structural Dynamics, vol. 43, no. 7, pp. 1067-1088, 2014.

[7] P. S. Harvey and H. P. Gavin, "Assessment of a rolling isolation system using reduced order structural models," Engineering Structures, vol. 99, pp. 708-725, 2015.

[8] M. Ismail and J. R. Casas, "Novel isolation device for protection of cable-stayed bridges against near-fault earthquakes," Journal of Bridge Engineering, vol. 19, no. 8, pp. 50-65, 2014.

[9] M. Ismail, J. Rodellar, and F. Pozo, "An isolation device for near-fault ground motions," Structural Control and Health Monitoring, vol. 21, no. 3, pp. 249-268, 2014.

[10] M. Ismail, "An isolation system for limited seismic gaps in near-fault zones," Earthquake Engineering \& Structural Dynamics, vol. 44, no. 7, pp. 1115-1137, 2015.

[11] S.-J. Wang, J.-S. Hwang, K.-C. Chang et al., "Sloped multiroller isolation devices for seismic protection of equipment and facilities," Earthquake Engineering \& Structural Dynamics, vol. 43, no. 10, pp. 1443-1461, 2014.

[12] N. A. Ortiz, C. Magluta, and N. Roitman, "Numerical and experimental studies of a building with roller seismic isolation bearings," Structural Engineering and Mechanics, vol. 54, no. 3, pp. 475-489, 2015.

[13] R. S. Jangid and Y. B. Londhe, "Effectiveness of elliptical rolling rods for base isolation," Journal of Structural Engineering, vol. 124, no. 4, pp. 469-472, 1998.
[14] R. S. Jangid, "Stochastic seismic response of structures isolated by rolling rods," Engineering Structures, vol. 22, no. 8, pp. 937-946, 2000.

[15] E. Y. Antonyuk and N. P. Plakhtienko, "Dynamic modes of one seismic-damping mechanism with frictional bonds," International Applied Mechanics, vol. 40, no. 6, pp. 702-708, 2004.

[16] Y. C. Ou, J. W. Song, and G. C. Lee, "A parametric study of seismic behavior of roller seismic isolation bearings for highway bridges," Earthquake Engineering and Structure Dynamics, vol. 39, no. 5, pp. 541-559, 2010.

[17] G. C. Lee, Y.-C. Ou, T. Niu, J. Song, and Z. Liang, "Characterization of a roller seismic isolation bearing with supplemental energy dissipation for highway bridges," Journal of Structural Engineering, vol. 136, no. 5, pp. 502-510, 2010.

[18] S. Cui, Integrated design methodology for isolated floor systems in single-degree-of-freedom structural fuse systems, State University of New York, Buffalo, NY, USA, Ph.D. dissertation, 2012.

[19] L. Guerreiro, J. Azevedo, and A. H. Muhr, "Seismic tests and numerical modeling of a rolling-ball isolation system," Journal of Earthquake Engineering, vol. 11, no. 1, pp. 49-66, 2007.

[20] C. S. Tsai, Y.-C. Lin, W.-S. Chen, and H. C. Su, “Tri-directional shaking table tests of vibration sensitive equipment with static dynamics interchangeable-ball pendulum system," Earthquake Engineering and Engineering Vibration, vol. 9, no. 1, pp. 103-112, 2010.

[21] K. Kurita, S. Aoki, Y. Nakanishi, K. Tominaga, and M. Kanazawa, "Fundamental characteristics of reduction system for seismic response using friction force," Journal of Civil Engineering and Architecture, vol. 5, no. 11, pp. 10421047, 2011.

[22] R. P. Nanda, P. Agarwal, and M. Shrikhande, "Base isolation system suitable for masonry buildings," Asian Journal of Civil Engineering (Building and Housing), vol. 13, no. 2, pp. 195202, 2012.

[23] D. Kosntantinidis and N. Makris, "Experimental and analytical studies on the response of freestanding laboratory equipment to earthquake shaking," Earthquake Engineering \& Structural Dynamics, vol. 38, no. 6, pp. 827-848, 2009.

[24] A. D. Lewis and R. M. Murray, "Variational principles for constrained systems: theory and experiment," International Journal of Non-Linear Mechanics, vol. 30, no. 6, pp. 793-815, 1995.

[25] B. Wei, P. Wang, X. He, and L. Jiang, "The impact of the convex friction distribution on the seismic response of a spring-friction isolation system," KSCE Journal of Civil Engineering, vol. 22, no. 4, pp. 1203-1213, 2018.

[26] L.-L. Chung, P.-S. Kao, C.-Y. Yang, L.-Y. Wu, and H.-M. Chen, "Optimal frictional coefficient of structural isolation system," Journal of Vibration and Control, vol. 21, no. 3, pp. 525-538, 2015.

[27] B. Wei, T. Yang, L. Jiang, and X. He, "Effects of uncertain characteristic periods of ground motions on seismic vulnerabilities of a continuous track-bridge system of high-speed railway," Bulletin of Earthquake Engineering, vol. 16, no. 9, pp. 3739-3769, 2018.

[28] O. E. Ozbulut and S. Hurlebaus, "A comparative study on the seismic performance of superelastic-friction base isolators against near-field earthquakes," Earthquake Spectra, vol. 28, no. 3, pp. 1147-1163, 2012.

[29] A. Abdulridha, D. Palermo, S. Foo, and F. J. Vecchio, "Behavior and modeling of superelastic shape memory alloy 
reinforced concrete beams," Engineering Structures, vol. 49, no. 2, pp. 893-904, 2013.

[30] B. Wei, C. J. Zuo, X. H. He, and Q. Y. Hu, "Earthquake isolation of a spring-damper-friction system with a convex friction distribution," Journal of Testing and Evaluation, vol. 47, no. 2, article 20170275, 2019.

[31] Y. Wang, Q. Wei, J. Shi, and X. Long, "Resonance characteristics of two-span continuous beam under moving high speed trains," Latin American Journal of Solids and Structures, vol. 7, no. 2, pp. 185-199, 2010.

[32] C. F. Yin and B. Wei, "Numerical simulation of a bridgesubgrade transition zone due to moving vehicle in Shuohuang heavy haul railway," Journal of Vibroengineering, vol. 15, no. 2, pp. 1062-1068, 2013.

[33] C. J. Begley and L. N. Virgin, "Impact response and the influence of friction," Journal of Sound and Vibration, vol. 211, no. 5, pp. 801-818, 1998.

[34] D. G. Flom and A. M. Bueche, "Theory of rolling friction for spheres," Journal of Applied Physics, vol. 30, no. 11, pp. 1725-1730, 1959.

[35] B. Wei, T. H. Yang, and L. Z. Jiang, "Influence of friction variability on isolation performance of a rolling-damper isolation system," Journal of Vibroengineering, vol. 17, no. 2, pp. 792-801, 2015.

[36] C.-S. Yim, A. K. Chopra, and J. Penzien, "Rocking response of rigid blocks to earthquakes," Earthquake Engineering \& Structural Dynamics, vol. 8, no. 6, pp. 565-587, 1980.

[37] H. Rahmani Samani, M. Mirtaheri, A. P. Zandi, and H. Bahai, "The effects of dynamic loading on hysteretic behavior of frictional dampers," Shock and Vibration, vol. 2014, Article ID 181534, 9 pages, 2014.

[38] H. Rahmani-Samani, M. Mirtaheri, and M. A. Hariri-Ardebili, "A frictional damping-based design methodology for structures," Proceedings of the Institution of Civil EngineersStructures and Buildings, vol. 169, no. 3, pp. 174-183, 2015.

[39] P.R. China Standard of the Ministry of Communications of, JTJ004-89 Specifications of Earthquake Resistant Design for Highway Engineering, China Communications Press, Beijing, China, 1989, in Chinese.

[40] B. Wei, C. Zuo, X. He, L. Jiang, and T. Wang, "Effects of vertical ground motions on seismic vulnerabilities of a continuous track-bridge system of high-speed railway," Soil Dynamics and Earthquake Engineering, vol. 115, pp. 281-290, 2018.

[41] B. Wei, P. Wang, X. H. He, and L. Z. Jiang, "Seismic isolation characteristics of a friction system," Journal of Testing and Evaluation, vol. 46, no. 4, pp. 1411-1420, 2018.

[42] S. M. Mirtaheri, M. Nazeryan, M. K. Bahrani, A. Nooralizadeh, L. Montazerian, and M. Naserifard, "Local and global buckling condition of all-steel buckling restrained braces," Steel and Composite Structures, vol. 23, no. 2, pp. 217-228, 2017.

[43] B. Wei, T. Yang, L. Jiang, and X. He, "Effects of friction-based fixed bearings on the seismic vulnerability of a high-speed railway continuous bridge," Advances in Structural Engineering, vol. 21, no. 5, pp. 643-657, 2018. 


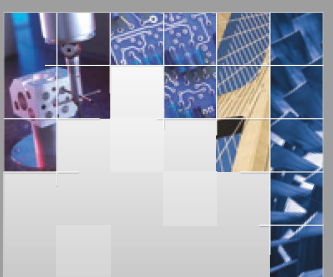

\section{Enfincering}
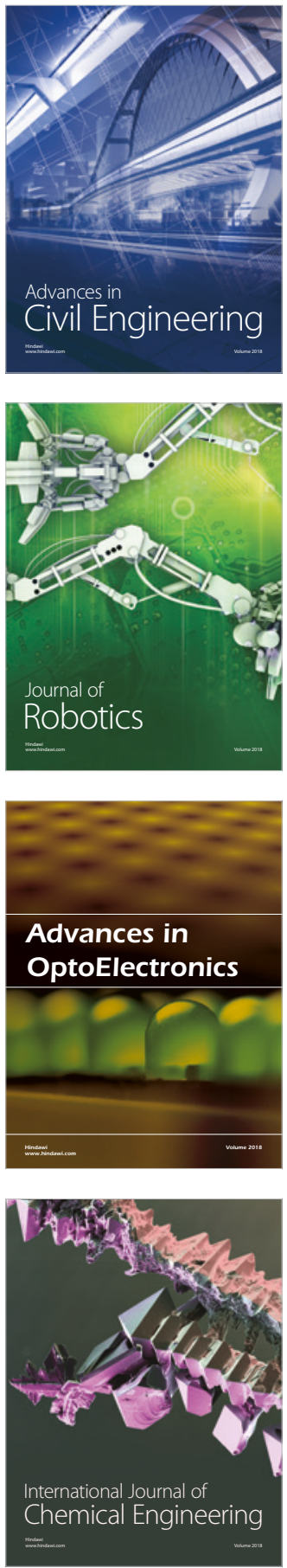

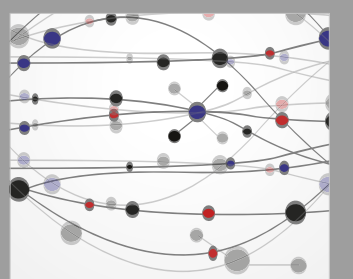

\section{Rotating \\ Machinery}

The Scientific World Journal

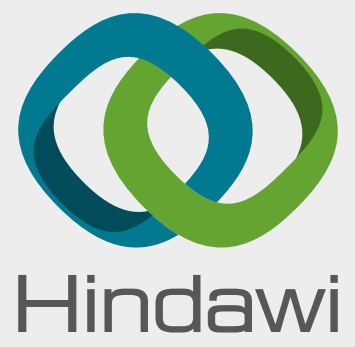

Submit your manuscripts at

www.hindawi.com
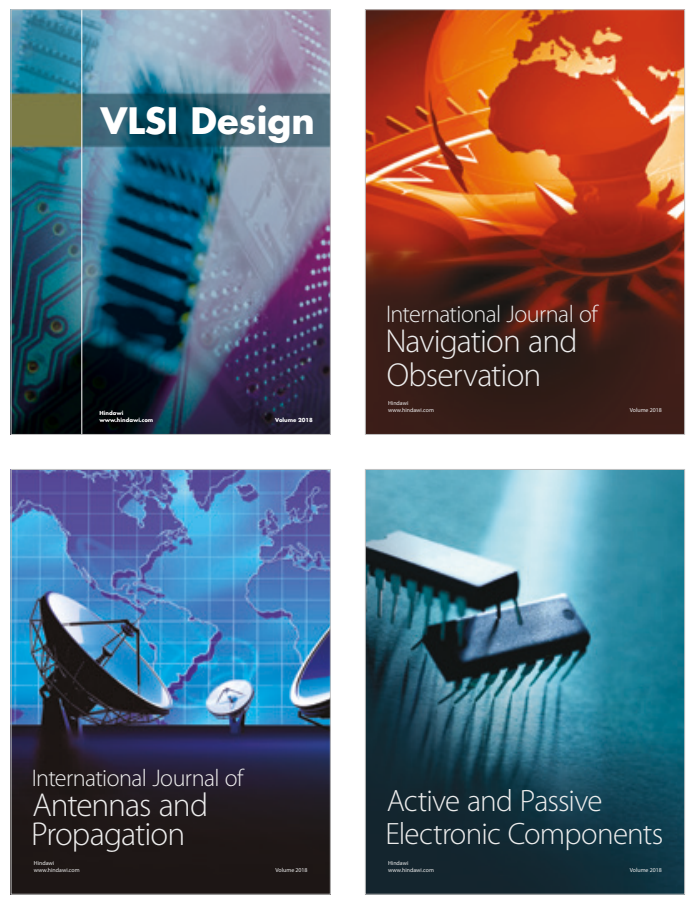
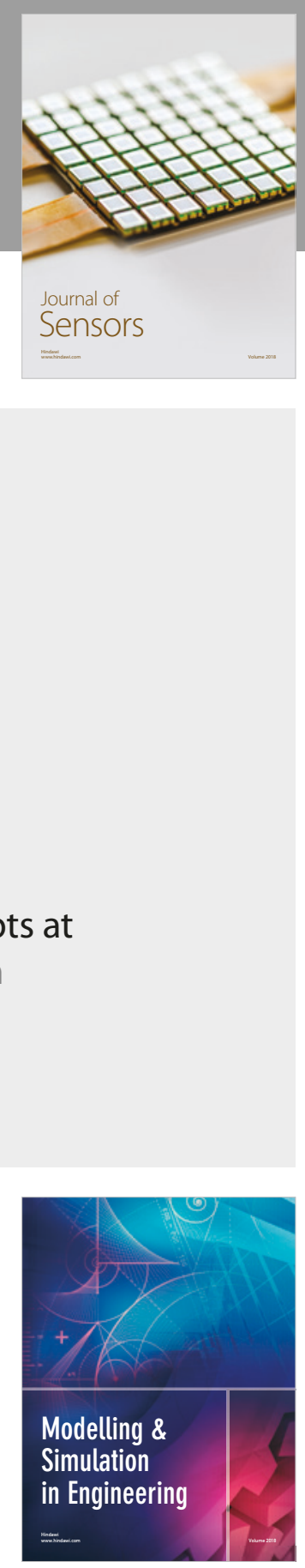

\section{Advances \\ Multimedia}
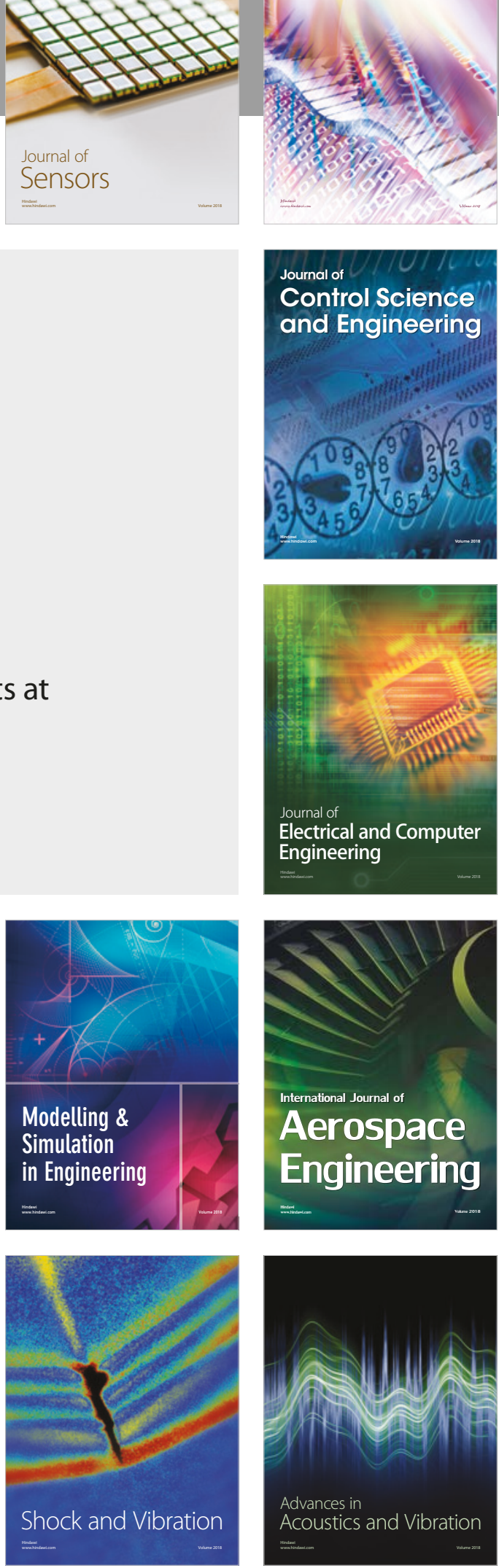